\title{
Copyright
}

by

Jonathan Steven Slowik

2012 
The Thesis Committee for Jonathan Steven Slowik

Certifies that this is the approved version of the following thesis:

\section{A Theoretical Analysis of the Influence of Wheelchair Seat Position on Upper Extremity Demand}

\section{APPROVED BY SUPERVISING COMMITTEE:}

Supervisor:

Richard R. Neptune

Sara J. Mulroy 


\title{
A Theoretical Analysis of the Influence of Wheelchair Seat Position on Upper Extremity Demand
}

\author{
by
}

Jonathan Steven Slowik, B.S.M.E.

\author{
Thesis \\ Presented to the Faculty of the Graduate School of \\ The University of Texas at Austin \\ in Partial Fulfillment \\ of the Requirements \\ for the Degree of \\ Master of Science in Engineering
}

The University of Texas at Austin

August 2012 


\section{Dedication}

This thesis is dedicated to my loving wife, Nicole, and our growing family. 


\section{Acknowledgements}

I would like to thank my advisor, Dr. Rick Neptune, for his guidance and contributions to my research and thesis. I am extremely grateful for all of his efforts to help me progress as both a researcher and a person. I would also like to thank Dr. Sara Mulroy for serving on my committee. It is an honor to have a thesis committee with such a tremendous amount of experience in the fields of biomechanics and rehabilitation. In addition, I am thankful for the support and encouragement that I have received from my colleagues in the Neuromuscular Biomechanics Lab.

I would also like to thank my parents and my sister for being amazing role models in both my engineering career and everyday life. My family and close friends have helped shape the person I am today, and they continue to be significant influences in my life. Furthermore, I would like to thank my wife, Nicole, for all of her tremendous love and support. I am thankful for her companionship and every moment that I have with her (and the rest of our little family).

I would also like to acknowledge the following sources of financial support: the Electrical Engineering Class of 1946 Endowed Graduate Fellowship in Engineering provided by the Cockrell School of Engineering, the National Science Foundation Graduate Research Fellowship Program and a grant from the National Institutes of Health. 


\title{
Abstract \\ A Theoretical Analysis of the Influence of Wheelchair Seat Position on Upper Extremity Demand
}

\author{
Jonathan Steven Slowik, M.S.E. \\ The University of Texas at Austin, 2012
}

Supervisor: Richard R. Neptune

The high demands of manual wheelchair propulsion put users at risk of additional pain and injury that can lead to further reductions in independence and quality of life. Seat position is an adjustable parameter that has been shown to influence propulsion biomechanics. As a result, a number of studies have attempted to optimize this position. However, due to complexities in quantifying upper extremity demand, seat position guidelines are often based on studies aimed at reducing indirect quantities (e.g., cadence, handrim forces, joint ranges of motion and muscle excitation levels) rather than more direct measures of demand (e.g., muscle stress and metabolic cost). Forward dynamics simulations provide an alternative approach to systematically investigate the influence of seat position on more direct measures of upper extremity demand. The objective of this study was to generate and analyze a set of forward dynamics simulations of wheelchair propulsion across the range of attainable seat positions to identify the optimal seat position that minimizes upper extremity demand (i.e., muscle stress, metabolic cost and muscle antagonism). The optimization results showed both metabolic cost and muscle 
stresses were near minimal values at superior/inferior positions corresponding to top dead center elbow angles between 110 and 120 degrees while at an anterior/posterior position with a hub-shoulder angle between -10 and -2.5 degrees. These minimal values coincided with a reduction in the level of antagonistic muscle activity, primarily at the glenohumeral joint. Seat positions that deviated from these minimal values increased the level of co-contraction required to maintain a stable, smooth propulsive stroke, and consequentially increased upper extremity demand. These results can provide guidelines for positioning the seat to help reduce upper extremity overuse injuries and pain, and thus improve the overall quality of life for wheelchair users. 


\section{Table of Contents}

List of Tables ............................................................................................. ix

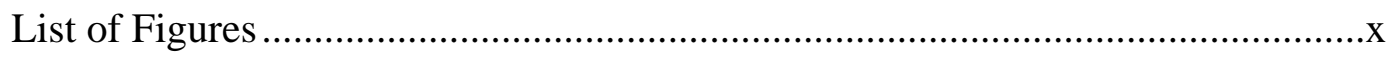

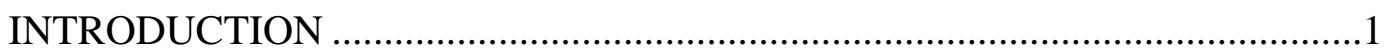

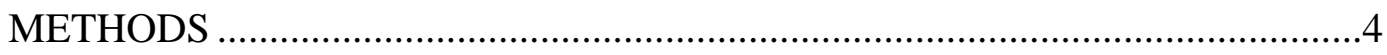

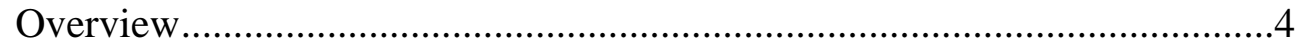

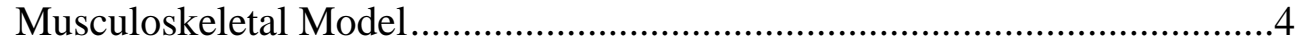

Manual Wheelchair Model .........................................................................7

Simulation of Wheelchair Propulsion......................................................10

Simulation Analysis........................................................................ 11

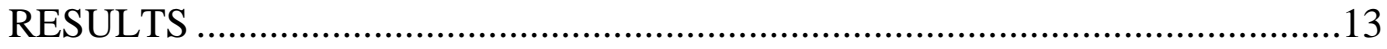

The Influence of Seat Position on Metabolic Cost .....................................14

The Influence of Seat Position on Muscle Stress ......................................15

The Influence of Seat Position on Muscle Antagonism .............................15

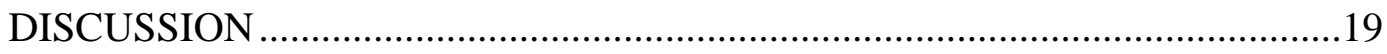

Limitations \& Future Work ...................................................................21

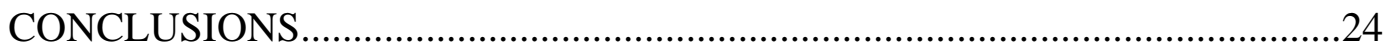

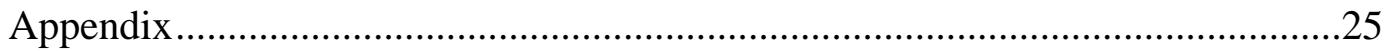

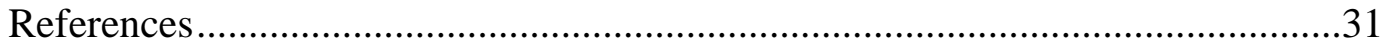

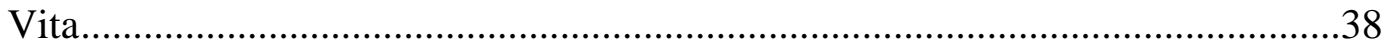




\section{List of Tables}

Table 1: $\quad$ Average differences between initial position simulation kinematics and group-averaged experimental kinematics of 12 experienced wheelchair users ...........................................................14

Table 2: $\quad$ Individual DOF excess torque values .................................................21

Table A1: $\quad$ Upper extremity musculoskeletal model parameters..........................25 


\section{List of Figures}

Figure 1: 3D musculoskeletal model used in the wheelchair propulsion

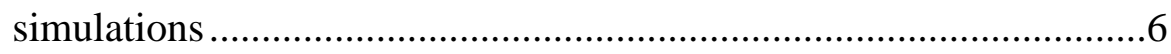

Figure 2: $\quad$ 2D model of wheelchair propulsion used to determine contact

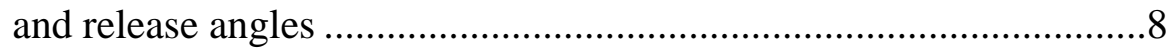

Figure 3: Initial position simulation hand path ……………………………....13

Figure 4: $\quad$ Normalized metabolic cost versus seat position ...................................16

Figure 5: Overall muscle stress versus seat position ..........................................17

Figure 6: Average excess torque versus seat position.......................................18

Figure A1: Plane of elevation excess torque versus seat position........................26

Figure A2: Elevation angle excess torque versus seat position ...........................27

Figure A3: Internal-external rotation excess torque versus seat position ............28

Figure A4: Elbow flexion-extension excess torque versus seat position.............29

Figure A5: Forearm pronation-supination excess torque versus seat position....30 


\section{INTRODUCTION}

There are approximately 3.3 million wheelchair users in the United States (CDC, 2009), with the vast majority (>90\%) of users relying on manual wheelchair propulsion as their primary method of mobility (Kaye et al., 2000). Upper extremity pain and injuries that frequently occur in wheelchair users (e.g., Boninger et al., 2005; Mercer et al., 2006) can be very debilitating and lead to a decrease in independence and quality of life (e.g., Pentland and Twomey, 1994; Gutierrez et al., 2007; Requejo et al., 2008a; Riggins et al., 2011). The high incidence of pain and injury is correlated with the high physical demand placed on the upper extremity during wheelchair propulsion (e.g., Boninger et al., 2005; Requejo et al., 2008a). In addition to generating the mechanical power required to propel the wheelchair, the upper extremity muscles must also help maintain joint stability (e.g., Requejo et al., 2008a; Requejo et al., 2008b). These stability requirements, along with the kinematic constraints of the push phase, require a large amount of intermuscular coordination and co-activation (e.g., van der Helm and Veeger, 1996; Rankin et al., 2010; Rankin et al., 2011; Rankin et al., 2012). Notably, the glenohumeral joint has relatively few stabilizing structures (PVACSCM, 2005), requiring the muscles responsible for stabilizing the joint to be highly active and have an elevated risk of injury (e.g., Veeger et al., 2002; Mulroy et al., 2004).

Seat position is an easily adjustable parameter that directly influences propulsion biomechanics (e.g., Boninger et al., 2000; Richter, 2001; Kotajarvi et al., 2004; Gorce and Louis, 2012) and upper extremity demand (e.g., Boninger et al., 2005; Gutierrez et al., 2005; Mulroy et al., 2005; Requejo et al., 2008a). Thus, identifying the optimal seat position that minimizes upper extremity demand holds great promise for reducing the risk of pain and injury. A number of studies have examined the influence of seat position on 
propulsion mechanics and found relationships with specific biomechanical measures such as cadence (e.g., Masse et al., 1992; Boninger et al., 2000; Richter, 2001; Kotajarvi et al., 2004; Gorce and Louis, 2012), handrim forces (e.g., Boninger et al., 2000; Kotajarvi et al., 2004; van der Woude et al., 2009), joint ranges of motion (e.g., Hughes et al., 1992; Wei et al., 2003; Gorce and Louis, 2012) and electromyography (EMG) activity (e.g., Masse et al., 1992; Gutierrez et al., 2005; Louis and Gorce, 2010). High levels of these measures have been identified as risk factors for upper extremity pain and injury (e.g., Boninger et al., 2005; Gutierrez et al., 2005; Gorce and Louis, 2012).

Recent clinical guidelines based on these relationships suggest that seat position should be adjusted as far posterior as possible without compromising user stability (PVACSCM, 2005). They also recommend superior/inferior positions that correspond to an elbow angle between $100^{\circ}$ and $120^{\circ}$ when the hand is at the top dead-center (TDC) position on the handrim (full extension is $180^{\circ}$ ). However, recent studies have found with such low, posterior seat positions, the joint ranges of motion and muscle activity levels may be increased (Louis and Gorce, 2010; Gorce and Louis, 2012) and adversely affect upper extremity demand.

One challenge of assessing the influence of seat position on upper extremity demand is the inability to directly measure demand-related quantities such as muscle stress or co-contraction that may elevate joint loading. Because these measures are difficult to obtain experimentally (Lin et al., 2004; Erdemir et al., 2007), indirect measures are frequently used. For example, inverse dynamics techniques are often used to determine joint torques, but identifying individual muscle force and stress is challenging due to muscle redundancy and co-contraction (Zajac et al., 2002, 2003; Erdemir et al., 2007). In addition, systematically investigating the influence of seat position on upper extremity demand using experimental techniques is difficult and time- 
consuming (e.g., to assess the influence of seat position on metabolic cost). As a result, most studies have investigated a limited number of seat positions (e.g., two or three).

Forward dynamics simulations provide an alternative approach to systematically examine the influence of wheelchair seat position on direct measures of upper extremity demand. Forward dynamics techniques have been successfully used to analyze various human movement tasks including pedaling (e.g., Raasch et al., 1997; Umberger et al., 2006; Rankin and Neptune, 2008), walking (e.g., Anderson and Pandy, 2001; Liu et al., 2006; McGowan et al., 2009) and running (e.g., Sasaki and Neptune, 2006; Miller et al., 2012). More recently, these techniques have been applied to analyze wheelchair propulsion to identify individual muscle contributions to push and recovery mechanics (e.g., Rankin et al., 2010; Rankin et al., 2011; Rankin et al., 2012). Simulations can also be used to systematically vary system parameters and analyze their influence on specific biomechanical measures. This technique has recently been used in the design of bicycle configurations (e.g., Rankin and Neptune, 2010) and lower limb prostheses (e.g., Fey et al., 2012).

The goal of this study was to use forward dynamics simulations of wheelchair propulsion to investigate how seat position influences upper extremity demand (i.e., muscle stress, metabolic cost and muscle antagonism). Understanding these relationships can help guide clinicians in determining the optimal wheelchair configurations that reduce upper extremity demand, and ultimately overuse injuries and pain in wheelchair users. 


\section{METHODS}

\section{Overview}

A 3D musculoskeletal model of the upper extremity was combined with a model of a standard wheelchair to create forward dynamics simulations of manual wheelchair propulsion. Seat position was systematically varied and its influence on muscle stress, metabolic cost and muscle antagonism was quantified. Below, the musculoskeletal and wheelchair models, simulation generation and analysis are described in detail.

\section{Musculoskeletal Model}

The musculoskeletal model used in this study was based on a previously described model of the upper extremity (Holzbaur et al., 2005; Rankin et al., 2010; Rankin et al., 2011; Rankin et al., 2012) and will be summarized here (Figure 1). The

model was developed using SIMM (Musculographics, Inc., Santa Rosa, CA, USA) and consisted of a trunk and right side upper arm, forearm and hand segments. There were three degrees-of-freedom (DOFs) at the shoulder, defined as plane of elevation, elevation angle and internal-external rotation, in accordance with the recommendations of the International Society of Biomechanics (Wu et al., 2005). The motion at the shoulder also included a scapulohumeral rhythm based on regression equations from cadaver data (Holzbaur et al., 2005). The model had two additional DOFs, elbow flexion-extension and forearm pronation-supination. The wrist was fixed in the standard anatomical position.

Twenty-six Hill-type musculotendon actuators (Table A1 in the Appendix) represented the major upper extremity muscles crossing the shoulder and elbow joints. Each actuator received its own excitation pattern, with the exception of three muscle 
groups: the two actuators that represented the sternocostal portion of the pectoralis major, the three latissimus dorsi actuators and the two actuators representing the lateral triceps and anconeus. Within each of these groups, the actuators received the same excitation pattern, resulting in a total of twenty-two independent excitation patterns. The actuators were governed by intrinsic muscle force-length-velocity relationships (Zajac, 1989). The muscle excitation-activation dynamics were modeled using a first-order differential equation (Raasch et al., 1997) with muscle-specific activation/deactivation time constants (Winters and Stark, 1988; Happee and van der Helm, 1995). Passive torques were applied at the shoulder and elbow to represent ligaments and other passive joint structures that limit extreme joint positions. The dynamic equations-of-motion were generated using SD/FAST (PTC, Needham, MA). 


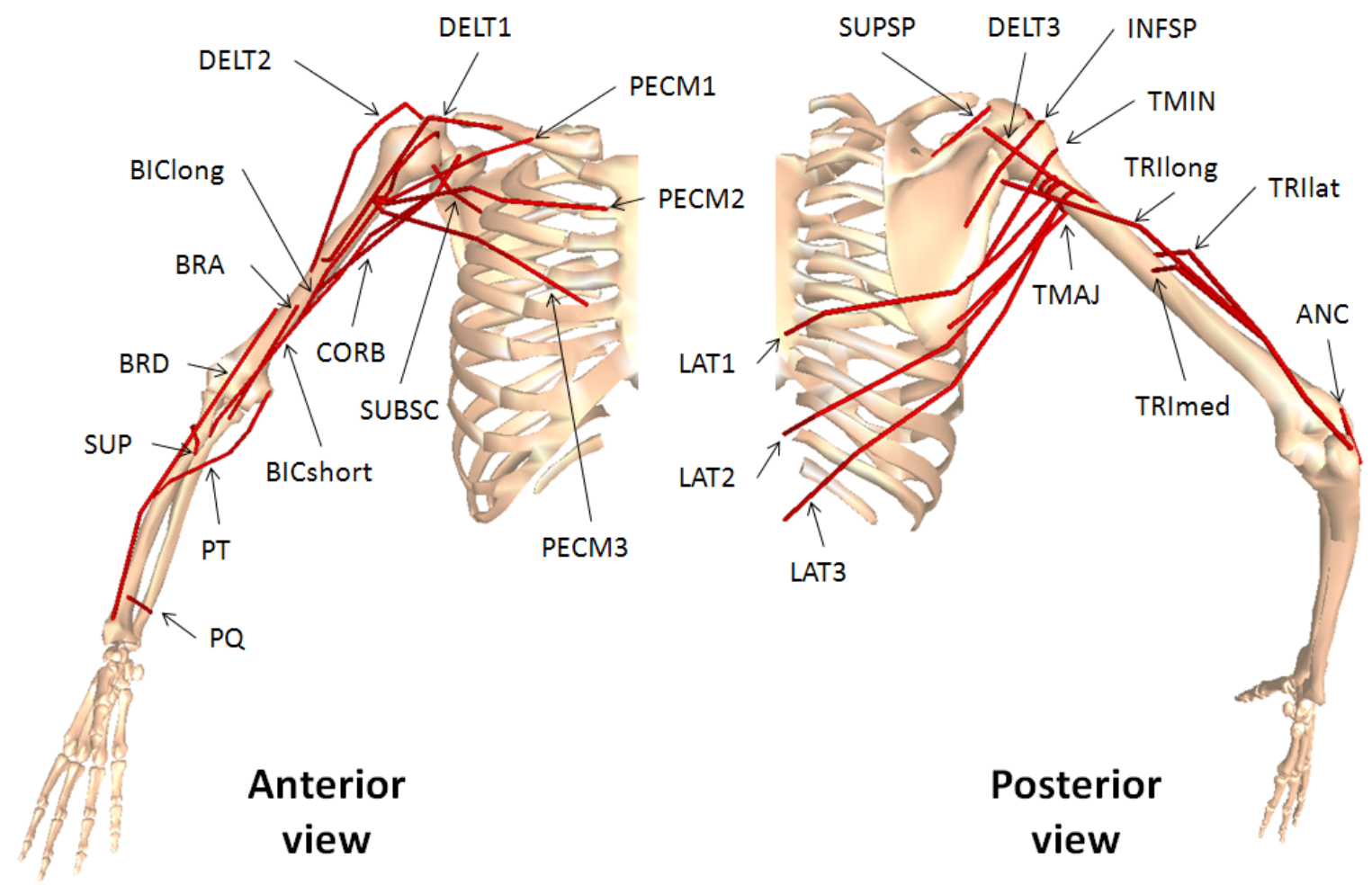

Figure 1: $\quad 3 D$ musculoskeletal model used in the wheelchair propulsion simulations. The model had 5 degrees-of-freedom: plane of elevation, elevation angle, internal-external rotation, elbow flexion-extension, and forearm pronationsupination. Twenty-six Hill-type musculotendon actuators represented the major upper extremity muscles crossing the shoulder and elbow joints. These actuators were: DELT1 (anterior deltoid), DELT2 (middle deltoid), DELT3 (posterior deltoid), PECM1 (pectoralis major, clavicular head), PECM2 (pectoralis major, sternocostal head portion 1 - sternum), PECM3 (pectoralis major, sternocostal head portion 2 - ribs), CORB (coracobrachialis), TMAJ (teres major), LAT1 (latissimus dorsi, thoracic portion), LAT2 (latissimus dorsi, lumbar portion), LAT3 (latissimus dorsi, iliac portion), SUBSC (subscapularis), INFSP (infraspinatus), TMIN (teres minor), SUPSP (supraspinatus), BRD (brachioradialis), BRA (brachialis), BICshort (biceps brachii, short head), BIClong (biceps brachii, long head), ANC (anconeus), TRIlat (triceps brachii, lateral head), TRImed (triceps brachii, medial head), TRIlong (triceps brachii, long head), SUP (supinator), PQ (pronator quadratus) and PT (pronator teres). 


\section{Manual Wheelchair Model}

A model of a standard manual wheelchair with circular handrims (radius $\left(R_{H R}\right)$ of $0.267 \mathrm{~m}$, rim-to-rim distance of $0.635 \mathrm{~m}$ ) was generated and combined with the musculoskeletal model by defining the position of the hip relative to the rear axle of the wheelchair. This position was kept fixed throughout each simulation of wheelchair propulsion and was systematically varied in both the superior/inferior and anterior/posterior directions to represent a wide range of seat positions. The motion of the third metacarpophalangeal joint was prescribed to follow a path on the circular handrim during the push phase, which was further defined by the contact $\left(\theta_{C}\right)$ and release $\left(\theta_{R}\right)$ angles. These angles were dependent on the seat position, and thus were calculated using a simple 2D model (Figure 2, based on Richter, 2001) as follows:

$$
\begin{aligned}
& L_{H S}=\sqrt{x_{H S}^{2}+y_{H S}^{2}} \\
& \theta_{H S}=\tan ^{-1}\left(\frac{x_{H S}}{y_{H S}}\right) \\
& \theta_{C}=0.9 *\left(\theta_{H S}-\cos ^{-1}\left[\frac{L_{H S}{ }^{2}+\left(R_{H R}+L_{F A}\right)^{2}-L_{U A}{ }^{2}}{2 L_{H S}\left(R_{H R}+L_{F A}\right)}\right]\right) \\
& \theta_{R}=0.9 *\left(\theta_{H S}+\cos ^{-1}\left[\frac{R_{H R}{ }^{2}+L_{H S}{ }^{2}-\left(L_{U A}+L_{F A}\right)^{2}}{2 R_{H R} L_{H S}}\right]\right)
\end{aligned}
$$

where

$L_{U A}=$ Length of the upper arm segment $(0.267 \mathrm{~m})$

$L_{F A}=$ Length of the forearm/hand segment $(0.333 \mathrm{~m})$

$x_{H S}=$ Anterior distance between the wheelchair axle/hub and the shoulder

$y_{H S}=$ Superior distance between the wheelchair axle/hub and the shoulder

$L_{H S}=$ Distance between the wheelchair axle/hub and the shoulder

$\theta_{H S}=$ Angle of the vector from the wheelchair axle/hub to the shoulder

$\theta_{C}=$ Contact angle

$\theta_{R}=$ Release angle 

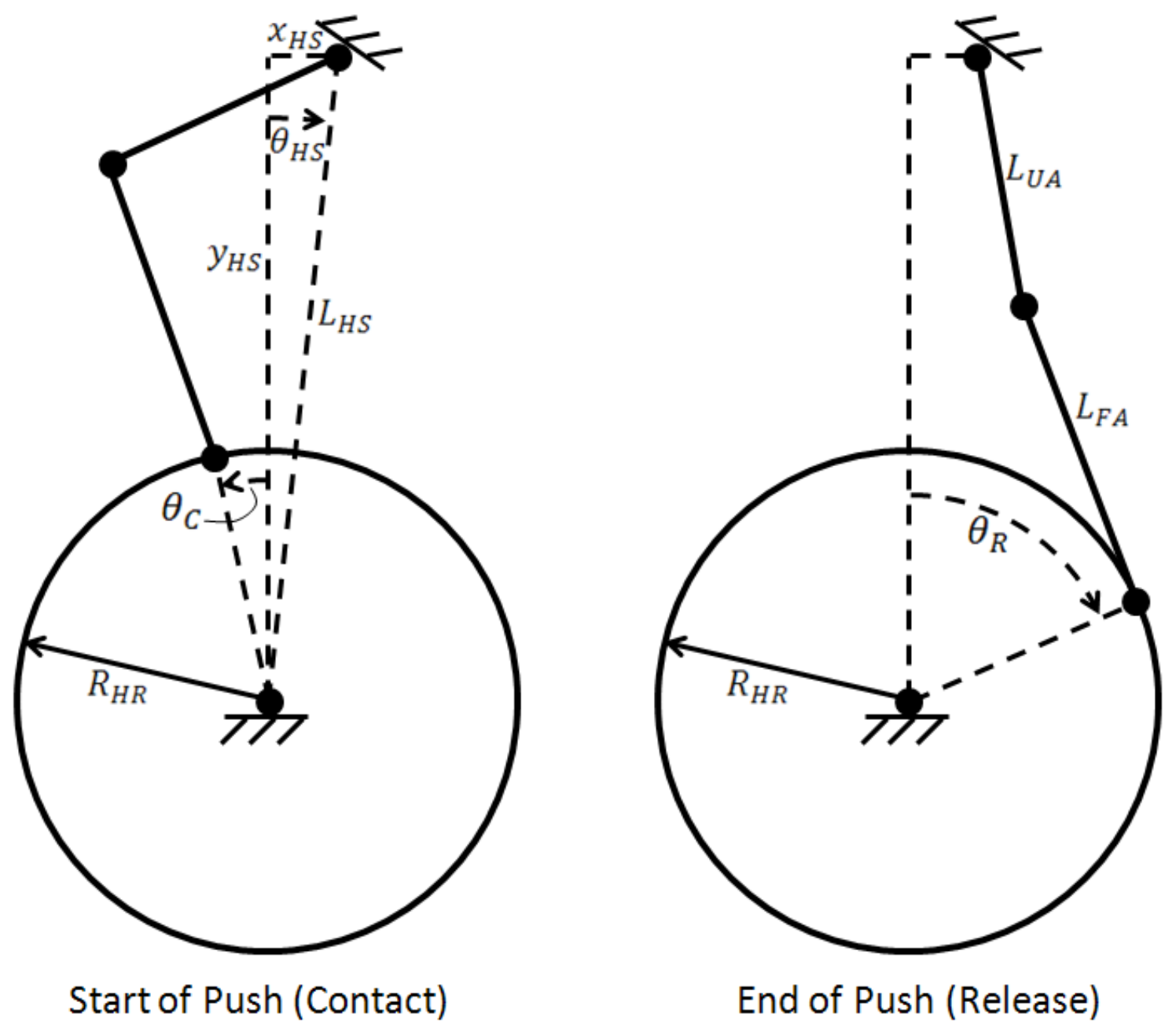

Figure 2: $\quad$ 2D model of wheelchair propulsion used to determine contact and release angles ( $\theta_{C}$ and $\theta_{R}$, respectively). The model consisted of an upper arm (length $=L_{U A}$ ), a forearm/hand segment (length $=L_{F A}$ ), and a wheel/handrim segment (radius $=R_{H R}$ ) with revolute joints at the shoulder, elbow, hand, and hub/axle. The shoulder was set at a fixed position relative to the hub/axle (total distance $=L_{H S}$, anterior/posterior component $=x_{H S}$, superior/inferior component $\left.=y_{H S}\right)$. 
The push angle $\left(\theta_{P}\right)$ was then defined as the difference between the release angle and contact angle as:

$$
\theta_{P}=\theta_{R}-\theta_{C}
$$

Additional constraints ensured that the simulations emulated realistic submaximal propulsion biomechanics. For all seat positions, the average power output to the handrim was set at 10W (Lin et al., 2009). For the initial seat position $\left(x_{H S}=0.0, y_{H S}=0.75 \mathrm{~m}\right)$, the push frequency $\left(f_{P}\right)$ was set at $1 \mathrm{~Hz}$ (PVACSCM, 2005), which is equivalent to a cycle time $\left(t_{C}\right)$ of 1 second. For all other seat positions, the push frequency was determined as:

$$
f_{P}=f_{P i}\left(\theta_{P i} / \theta_{P}\right)
$$

where $f_{P i}$ is the push frequency for the initial simulation and $\theta_{P i}$ is the push angle for the initial simulation (Richter, 2001).

The push time $\left(t_{P}\right)$ was set to $40 \%$ of the cycle time (Lin et al., 2009). Three propulsion cycles were simulated, and differences between the 3rd cycle initial and final joint angles, velocities and accelerations were minimized to replicate the periodic nature of propulsion. From the initial seat position $\left(x_{H S}=0.0, y_{H S}=0.75 \mathrm{~m}\right)$, the position was systematically varied independently in the superior/inferior direction ( $0.05 \mathrm{~m}$ increments) and the anterior/posterior direction ( $0.10 \mathrm{~m}$ increments) throughout the range of feasible seat positions. This resulted in 53 seat positions with $x_{H S}$ values that ranged from $-0.5 \mathrm{~m}$ to $0.4 \mathrm{~m}$ and $y_{H S}$ values that ranged from $0.35 \mathrm{~m}$ to $0.85 \mathrm{~m}$. 


\section{Simulation of Wheelchair Propulsion}

To simulate manual wheelchair propulsion at each seat position, we used dynamic optimization to identify the muscle excitation patterns that minimized the change in hand force and joint torques produced by the muscles (described below). The excitation pattern $(u(t))$ of each muscle group was defined as a sum of four Henning patterns (e.g., Rankin et al., 2011):

$$
u(t)=\sum_{i=1}^{4} u_{i}(t)
$$

where $u_{i}(t)$ is the excitation value at time $t$ for the ith Henning pattern. Each Henning pattern was defined as:

$$
u_{i}(t)=\left\{\begin{array}{cc}
\frac{m_{i}}{2}\left[1-\cos \left(\frac{2 \pi\left(t-a_{i}\right)}{b_{i}-a_{i}}\right)\right] & , a_{i} \leq t \leq b_{i} \\
0 & \text { otherwise }
\end{array}\right.
$$

where $m_{i}, a_{i}$ and $b_{i}$ are the magnitude, onset and offset respectively. This resulted in 12 parameters for each muscle group (264 total parameters).

A simulated annealing optimization algorithm (Goffe et al., 1994) was used to find the optimal muscle excitation parameters that simulated wheelchair propulsion and minimized the change in hand force and torques (Ohta et al., 2004), with the cost function defined as:

$$
J=\int_{0}^{t_{c}}\left(\dot{F}^{T} \dot{F}+w \dot{\tau}^{T} \dot{\tau}\right) d t
$$


where $\dot{F}$ is the vector containing the time derivatives of tangential, radial and lateral components of the handrim force (in units of $\mathrm{N}$ ), $\dot{\tau}$ is the vector of the time derivatives of the joint torques produced by individual muscle forces $(\mathrm{Nm})$, and $w$ is a weighting factor $\left(\mathrm{m}^{-2}\right)$. The weighting factor was set at $50 \mathrm{~m}^{-2}$.

\section{Simulation Analysis}

To ensure that the simulation had reached steady-state, all simulation analyses were performed on the 3rd propulsion cycle. The seat positions were originally defined as anterior and superior offsets from the initial position $\left(x_{H S}=0.0, y_{H S}=0.75 \mathrm{~m}\right)$ with negative numbers denoting posterior and inferior positions, but in order to transform these positions into a coordinate system that scales with subject anthropometry, the elbow flexion angle and the angle of the hub-shoulder vector were also determined when the hand was at TDC. For the initial seat position, simulation kinematics were compared to the group-averaged experimental kinematics of 12 experienced wheelchair users (from Rankin et al., 2011). For all seat positions, metabolic cost and individual muscle stresses were calculated.

Metabolic cost was calculated using a previously described model (Umberger et al., 2003; Umberger, 2010) by determining the rate of metabolic energy expenditure at each time step and integrating over the entire cycle. This value was then normalized by the total work done on the handrim throughout the cycle.

At each time step, individual muscle stress (muscle force divided by the physiological cross-sectional area) was calculated. Individual muscle stresses were then averaged across all of the muscles over the entire cycle to provide a measure of the overall upper extremity muscle stress $\left(\sigma_{u e}\right)$ : 


$$
\sigma_{u e}=\frac{1}{t_{c}} \int_{0}^{t_{c}}\left(\frac{1}{n} \sum_{i=1}^{n} \sigma_{i}(t)\right) d t
$$

where $n$ is the number of total muscles in the musculoskeletal model.

Finally, muscle antagonism was investigated as a potential cause of increased upper extremity demand by determining the average total magnitude of joint torques produced by the muscle forces $\left(\tau_{\text {total }}\right)$ and average net torque produced by the combination of these muscle torques $\left(\tau_{\text {net }}\right)$ and quantifying the excess torque $\left(\tau_{\text {excess }}\right)$ as follows:

$$
\begin{aligned}
& \tau_{\text {total }}=\frac{1}{n_{\text {dof }}^{* t} t_{c}} \int_{0}^{t_{c}}\left(\sum_{j=1}^{n_{\text {dof }}} \sum_{i=1}^{n_{\text {mus }}}\left|\tau_{i, \mathrm{j}}(t)\right|\right) d t \\
& \tau_{\text {net }}=\frac{1}{n_{\text {dof }} * t_{c}} \int_{0}^{t_{c}}\left(\left|\sum_{\mathrm{j}=1}^{n_{\text {dof }}} \sum_{i=1}^{n_{\text {mus }}} \tau_{i, \mathrm{j}}(t)\right|\right) d t \\
& \tau_{\text {excess }}=\tau_{\text {total }}-\tau_{\text {net }}
\end{aligned}
$$

where $n_{m u s}$ is the number of total muscles in the musculoskeletal model and $n_{d o f}$ is the number of DOFs being examined.

Three-dimensional surfaces were then created by plotting each measure of demand with respect to seat position, and these plots were used to identify the influence of seat position on upper extremity demand. 


\section{RESULTS}

The forward dynamics simulations successfully produced the manual wheelchair propulsion task. They all used an under-rim recovery pattern, which is characterized by the hand dropping below the handrim as it returns to the position of initial handrim contact (e.g., Kwarciak et al., 2009; Figure 3) This type of recovery pattern is recommended by recent guidelines (e.g., PVACSCM, 2005; Kwarciak et al., 2012). The average difference between the experimental and initial position simulation kinematics was 1.5 standard deviations (Table 1).

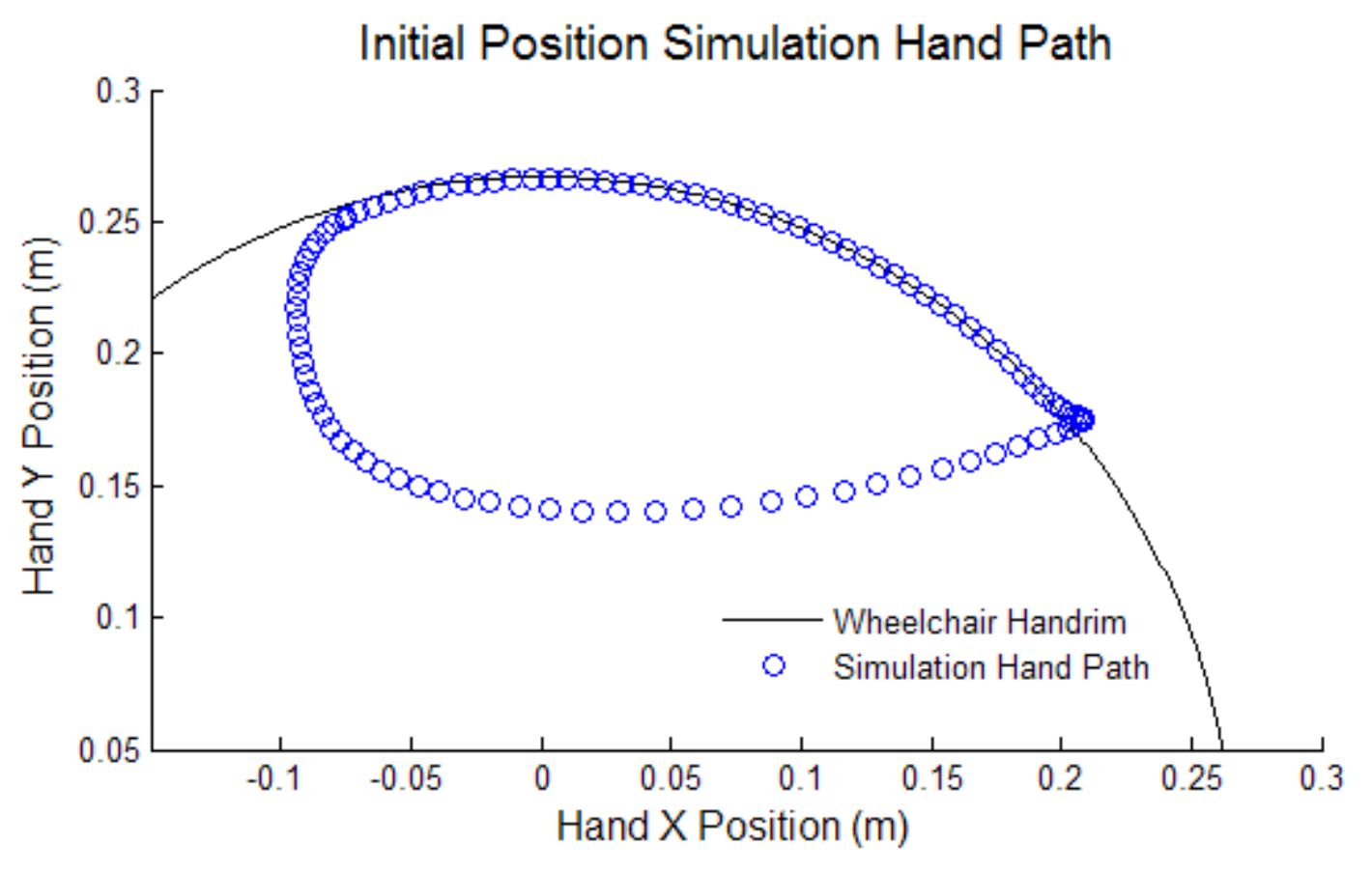

Figure 3: Initial position simulation hand path. The wheelchair handrim is represented by the solid black line, and the simulation hand path is represented by the blue circles. 
Table 1: $\quad$ Average differences between initial position simulation kinematics and group-averaged experimental kinematics of 12 experienced wheelchair users (from Rankin et al., 2011). Values are given in both degrees and numbers of standard deviations.

\begin{tabular}{|c|c|c|}
\hline & $\begin{array}{c}\text { Simulation Difference } \\
\text { (Degrees) }\end{array}$ & $\begin{array}{c}\text { Simulation Difference (\# of } \\
\text { Experimental SDs) }\end{array}$ \\
\hline Plane of Elevation & 8.7 & 1.5 \\
\hline Elevation Angle & 7.5 & 0.5 \\
\hline Internal-External Rotation & 16.4 & 1.1 \\
\hline Elbow Flexion-Extension & 23.0 & 1.8 \\
\hline Forearm Pronation-Supination & 31.5 & 2.4 \\
\hline All Degrees-of-Freedom & 17.4 & 1.5 \\
\hline
\end{tabular}

Across the range of seat positions, there were clear regions where metabolic cost, muscle stress and muscle antagonism were minimized.

\section{The Influence of Seat Position on Metabolic Cost}

The normalized metabolic cost (Figure 4) was minimized (8.5 J) at a seat position with anterior and superior offsets from the initial position of $-0.15 \mathrm{~m}$ and $-0.03 \mathrm{~m}$, respectively (hub-shoulder angle: $-11.6^{\circ}$, TDC elbow angle: $106.6^{\circ}$ ). Seat positions with anterior offsets between $-0.20 \mathrm{~m}$ and $0.13 \mathrm{~m}$ (hub-shoulder angle: between $-15^{\circ}$ and $10^{\circ}$ ) and superior offsets between $-0.05 \mathrm{~m}$ and $0.03 \mathrm{~m}$ (TDC elbow angle: between $100^{\circ}$ and $120^{\circ}$ ) had an associated normalized metabolic cost less than 10J. The maximum level among the seat positions investigated (22.3J) occurred at a seat position with anterior and superior offsets of $-0.50 \mathrm{~m}$ and $-0.35 \mathrm{~m}$, respectively (hub-shoulder angle: $-51.1^{\circ}$, TDC elbow angle: $110.0^{\circ}$ ). 


\section{The Influence of Seat Position on Muscle Stress}

The overall muscle stress (Figure 5) was minimized $(72.2 \mathrm{kPa}, 9.0 \%$ of the maximum possible stress level) at a seat position with anterior and superior offsets of $-0.16 \mathrm{~m}$ and $0.01 \mathrm{~m}$ (hub-shoulder angle: $-11.5^{\circ}$, TDC elbow angle: $116.9^{\circ}$ ). Seat positions with anterior offsets between $-0.20 \mathrm{~m}$ and $-0.01 \mathrm{~m}$ (hub-shoulder angle: between $-15^{\circ}$ and $0^{\circ}$ ) and superior offsets between $-0.03 \mathrm{~m}$ and $0.03 \mathrm{~m}$ (TDC elbow angle: between $105^{\circ}$ and $\left.120^{\circ}\right)$ had an associated overall muscle stress level less than $85 \mathrm{kPa}(10.6 \%$ of the maximum possible stress level). The maximum level among the seat positions investigated (150.2 $\mathrm{kPa}, 18.8 \%$ of the maximum possible stress level) occurred at a seat position with anterior and superior offsets of $-0.10 \mathrm{~m}$ and $0.10 \mathrm{~m}$, respectively (hubshoulder angle: $-6.4^{\circ}$, TDC elbow angle: $149.6^{\circ}$ ).

\section{The Influence of Seat Position on Muscle Antagonism}

The average excess torque across all DOFs (Figure 6) was minimized (4.6 Nm) at a seat position with anterior and superior offsets of $-0.09 \mathrm{~m}$ and $0.04 \mathrm{~m}$ (hub-shoulder angle: $-6.4^{\circ}$, TDC elbow angle: $122.2^{\circ}$ ). Seat positions with anterior offsets between $-0.14 \mathrm{~m}$ and $-0.03 \mathrm{~m}$ (hub-shoulder angle: between $-10^{\circ}$ and $-2.5^{\circ}$ ) and superior offsets between $-0.01 \mathrm{~m}$ and $0.05 \mathrm{~m}$ (TDC elbow angle: between $110^{\circ}$ and $130^{\circ}$ ) had an average excess torque of less than $5 \mathrm{Nm}$. The maximum average excess torque among the seat positions investigated $(14.0 \mathrm{Nm})$ occurred at a seat position with anterior and superior offsets of $0.30 \mathrm{~m}$ and $-0.10 \mathrm{~m}$, respectively (hub-shoulder angle: $25.1^{\circ}$, TDC elbow angle: $\left.117.5^{\circ}\right)$. 


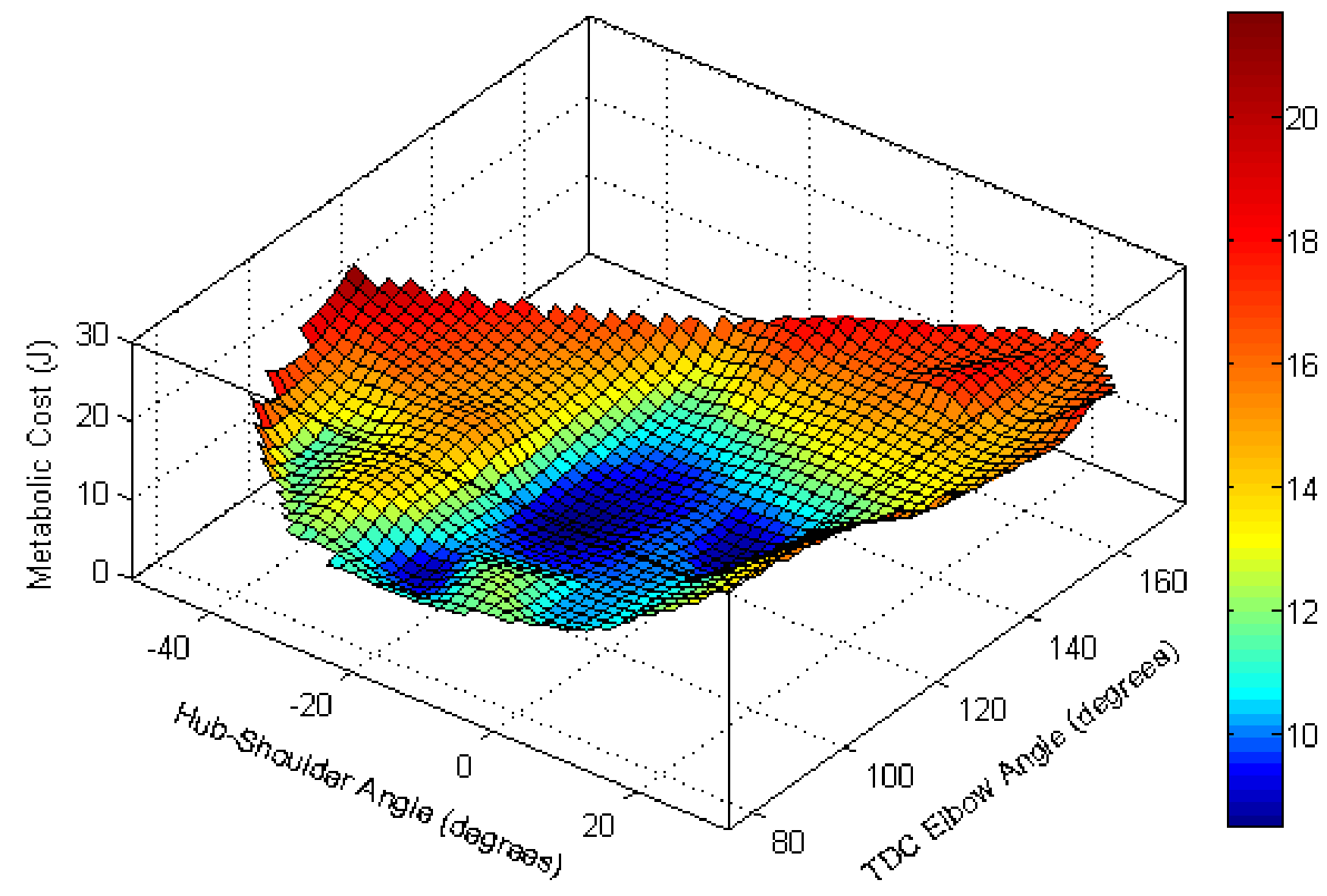

Figure 4: Normalized metabolic cost versus seat position. Metabolic cost was normalized by the total work done on the handrim throughout the cycle. Seat position is defined by the hub-shoulder angle and the elbow angle when the hand is at TDC. 


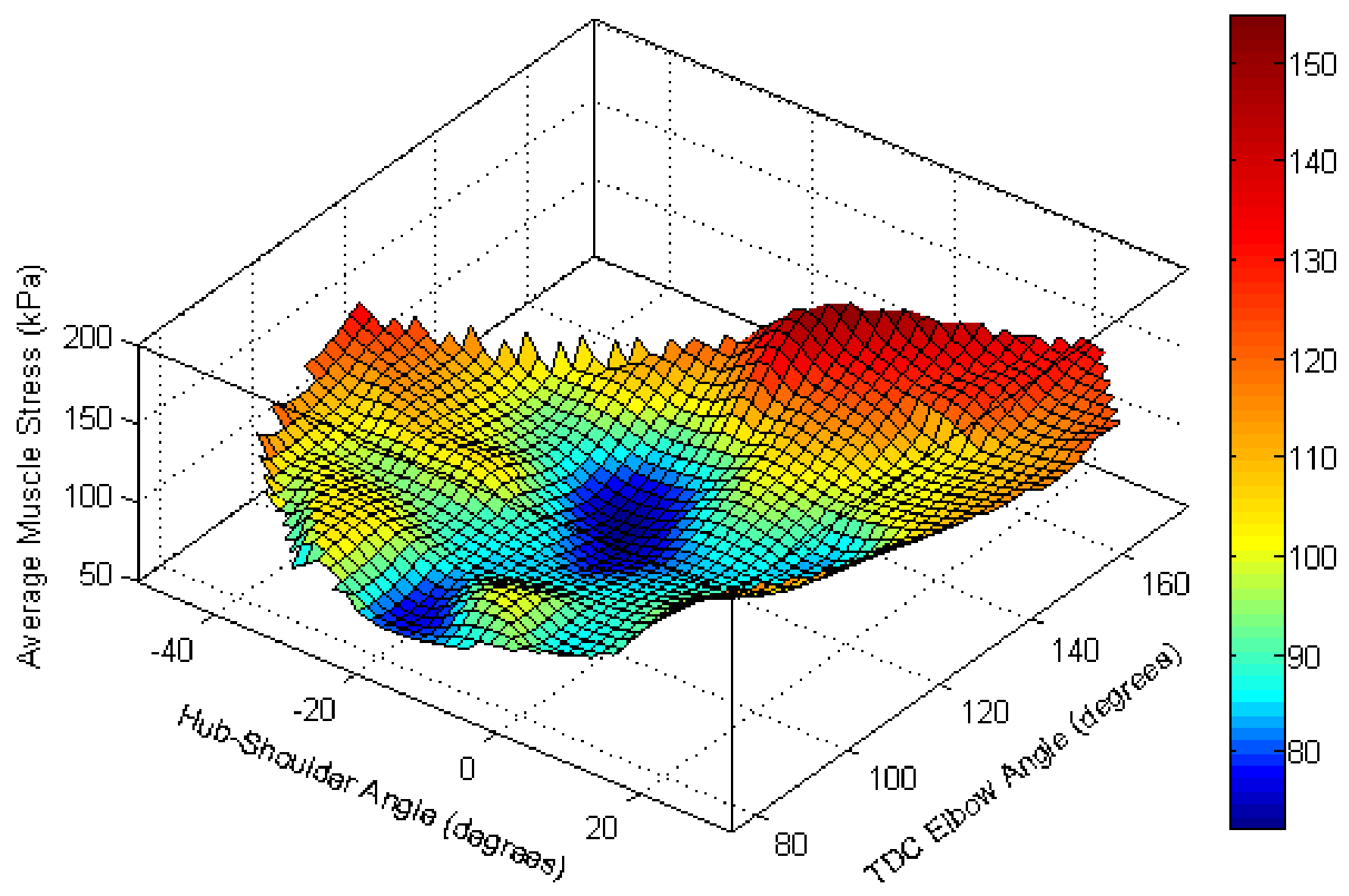

Figure 5: Overall muscle stress versus seat position. Individual muscle stresses were computed by dividing the muscle force by the physiological cross-sectional area, and then these values were averaged across all 26 muscles and across the entire propulsion cycle to calculate the overall muscle stress. Seat position is defined by the hub-shoulder angle and the elbow angle when the hand is at TDC. 


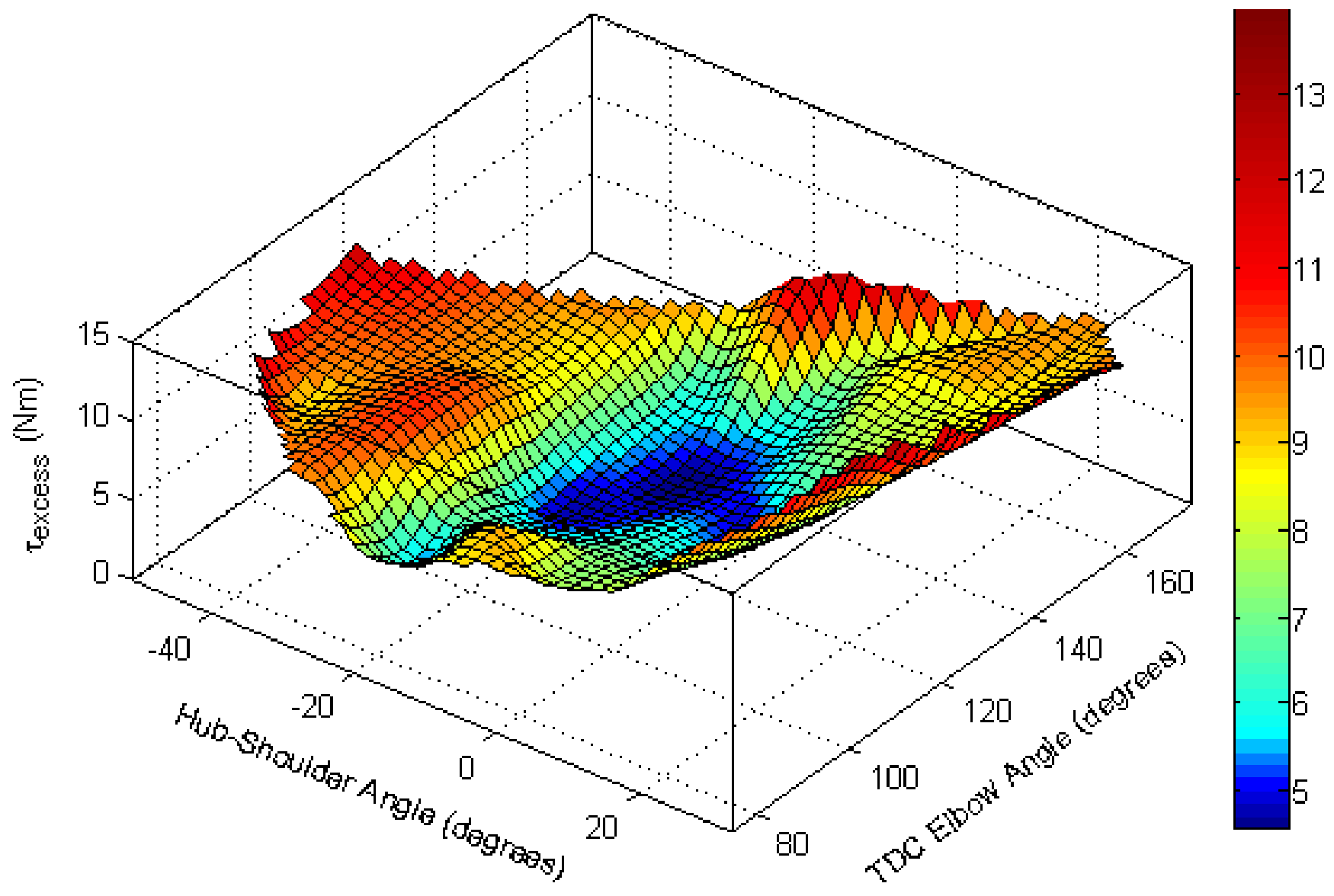

Figure 6: Average excess torque versus seat position. Average excess torque is the time-averaged difference between the total torque and the net torque, averaged across all degrees-of-freedom. Seat position is defined by the hub-shoulder angle and the elbow angle when the hand is at TDC. 


\section{DISCUSSION}

The goal of this study was to identify the influence of wheelchair seat position on upper extremity demand using a 3D musculoskeletal model and forward dynamics simulations of manual wheelchair propulsion. This approach allowed a detailed analysis of direct measures of upper extremity demand (i.e., muscle stress, metabolic cost and muscle antagonism) across the range of feasible seat positions. Muscle stress, metabolic cost and muscle antagonism were all near minimum values at seat positions with an anterior offset between $-0.14 \mathrm{~m}$ and $-0.03 \mathrm{~m}$ (hub-shoulder angle: between $-10^{\circ}$ and $-2.5^{\circ}$ ) and a superior offset between $-0.01 \mathrm{~m}$ and $0.03 \mathrm{~m}$ (TDC elbow angle: between $110^{\circ}$ and $\left.120^{\circ}\right)$

The optimal seat superior/inferior positions identified are similar to the recommendations of previous investigators (e.g., PVACSCM, 2005; Requejo et al., 2008a; van der Woude et al., 2009). An early study suggested that biomechanical efficiency is maximized at seat superior/inferior positions between $100^{\circ}$ and $120^{\circ}$ TDC elbow angle (van der Woude et al., 1989), while a more recent study expanded that range to include $130^{\circ}$ (van der Woude et al., 2009).

One study analyzing muscle activity recommended low seat superior/inferior positions (Masse et al., 1992) while another warned against moving too low (Louis and Gorce, 2010). While it has also been cautioned that joint ranges of motion increase with lower seat positions (e.g., Wei et al., 2003; Gorce and Louis, 2012), seat superior/inferior position recommendations based on spatiotemporal variables such as cadence and push angle advocate TDC elbow angles between $100^{\circ}$ and $120^{\circ}$ (e.g., PVACSCM, 2005; Requejo et al., 2008a).

The results of the current study suggest that upper extremity demand is minimized at superior/inferior seat positions with TDC elbow angles between $110^{\circ}$ and $120^{\circ}$. 
Increased muscle stress, metabolic cost and muscle antagonism resulted from seat positions outside this range. This occurred despite the improvements in push angles and cadences that accompanied more inferior positions and the favorable reductions in joint ranges of motion that accompanied more superior positions.

Most seat position studies have only examined seat positions where the shoulder is either anterior or slightly posterior to the axle, which is likely due to wheelchair stability concerns. As a result, whether their recommendations have been based on improving muscle activity (e.g., Gutierrez et al., 2005), spatiotemporal variables (e.g., Boninger et al., 2000), kinetics (e.g., Mulroy et al., 2005), additional confounding effects such as rolling resistance (e.g., Brubaker, 1986), or a combination of these factors (e.g., PVACSCM, 2005; Requejo et al., 2008a), studies have often concluded that the seat should be set in the most posterior position. However, our results suggest there is a limit to how far posterior to position the seat, as we found that some measures of upper extremity demand increase once you move posterior beyond the $-10^{\circ}$ hub-shoulder angle.

The range of seat positions at which muscle antagonism, as quantified by the average excess torque, was minimized was similar to the seat position ranges that minimized both metabolic cost and muscle stress. Because higher levels of antagonistic muscle torques appeared to cause higher upper extremity demand, the individual DOF contributions to the average excess torque values were examined to determine which muscle torques are most influenced by seat position. Minimum values for all DOFs were found at TDC elbow angles between $114.7^{\circ}$ and $123.2^{\circ}$, while the anterior/posterior positions varied from $-35^{\circ}$ to $-3.7^{\circ}$ hub-shoulder angle (Table 2). The torque associated with the elevation angle was the largest contributor to the DOF-average excess torque, while the torques associated with the other two glenohumeral joint DOFs were the next largest. In addition, the torque associated with plane of elevation had the largest percent 
difference between its minimum and maximum values. Consequently, the trends of the antagonistic muscles of the glenohumeral joint predominantly influenced the average excess torque trends. This highlights the importance of the muscles crossing the glenohumeral joint to manual wheelchair propulsion and the influence of seat position on the potential for injury to these muscles.

Table 2: $\quad$ Individual DOF excess torque values. Minimum values for each DOF and their associated hub-shoulder angles and TDC elbow angles are provided. Maximum values are provided for comparison.

\begin{tabular}{|c|c|c|c|c|c|c|c|}
\hline & & $\begin{array}{l}\text { Plane of } \\
\text { Elevation }\end{array}$ & $\begin{array}{c}\text { Elevation } \\
\text { Angle }\end{array}$ & $\begin{array}{l}\text { Internal- } \\
\text { External } \\
\text { Rotation }\end{array}$ & $\begin{array}{c}\text { Elbow } \\
\text { Flexion- } \\
\text { Extension }\end{array}$ & $\begin{array}{c}\text { Forearm } \\
\text { Pronation- } \\
\text { Supination }\end{array}$ & $\begin{array}{c}\text { Average } \\
\text { (all } \\
\text { DOFs) }\end{array}$ \\
\hline \multirow{3}{*}{$\begin{array}{c}\text { Minimum } \\
\text { Excess } \\
\text { Torque }\end{array}$} & $\begin{array}{c}\text { Hub- } \\
\text { Shoulder } \\
\text { Angle }\left(^{\circ}\right)\end{array}$ & -5.9 & -6.3 & -3.7 & -34.3 & -35.0 & -6.4 \\
\hline & $\begin{array}{c}\text { TDC } \\
\text { Elbow } \\
\text { Angle }\left(^{\circ}\right)\end{array}$ & 119.9 & 120.8 & 123.2 & 114.7 & 118.9 & 122.2 \\
\hline & $\begin{array}{l}\text { Value } \\
\text { (Nm) }\end{array}$ & 1.9 & 8.0 & 4.2 & 3.4 & 1.3 & 4.6 \\
\hline \multicolumn{2}{|c|}{$\begin{array}{l}\text { Maximum Excess } \\
\text { Torque Value (Nm) }\end{array}$} & 20.8 & 28.2 & 15.6 & 13.3 & 4.8 & 14.0 \\
\hline
\end{tabular}

\section{Limitations \& Future Work}

A potential limitation of this study is that it did not consider the range of propulsion techniques utilized by wheelchair users. Spatial (i.e. contact angle, release angle) and temporal (i.e. push time, cadence) variables are influenced by propulsion technique and differences in upper extremity impairment (e.g., Newsam et al., 1996; Finley et al., 2004; Mulroy et al., 2004), training (e.g., Rodgers et al., 2001; Rice et al., 2010; Richter et al., 2011) and terrain (e.g., Newsam et al., 1996; Richter et al., 2007; 
Chow et al., 2009; Cowan et al., 2009). The wheelchair propulsion technique analyzed in this study was derived from representative spatiotemporal values (e.g., Richter, 2001; PVACSCM, 2005; Lin et al., 2009), but other techniques exist. Thus, future work should consider analyzing other techniques. In addition, inter-subject variability in body anthropometrics was not considered, with the musculoskeletal model representing a 50th percentile able-bodied male. However, the physical capacity of wheelchair users varies with age, gender and nature of impairment and is generally less than that of nonwheelchair users (e.g., Janssen et al., 2002; Haisma et al., 2006). Future work should include the development of subject-specific models (e.g., Zajac et al., 2002; Fregly et al., 2012) to help determine the optimal seat position for individual users.

Another potential limitation is that the model consisted of only the right half of the upper extremity and assumed symmetry. Although a recent study has suggested that wheelchair propulsion is not a completely symmetric movement (Hurd et al., 2008), most wheelchair users utilize a symmetric propulsion technique (Goosey-Tolfrey and Kirk, 2003), and therefore the influence of asymmetries on the results would likely be small. In addition, the model was further simplified by fixing the wrist joint in the standard anatomical position, even though movement at the wrist joint can create a moment at the handrim. The absence of this moment may require an increase in elbow extensor activity (Veeger, 1999). However, wrist moments are much lower than those at the elbow and shoulder joints (e.g., Robertson et al., 1996; Guo et al., 2003; Sabick et al., 2004; Guo et al., 2006), and this increase would likely be seen across all seat positions. Thus, the fixed wrist was deemed to have a minimal influence on the results and conclusions of this study.

Another potential limitation is that the model did not include all of the trunk and wrist muscles, which could influence the metabolic cost estimates. However, the 
metabolic cost values corresponded to biomechanical efficiencies between $4.5 \%$ and 11.7\%, which were similar to previously reported values (e.g., Goosey et al., 1998; Hintzy and Tordi, 2004; van der Woude et al., 2009). In addition, this study considered relative differences across seat positions; therefore, the lack of these muscles would likely not influence the study conclusions.

Finally, there is uncertainty in which criteria the neuromuscular control system uses to resolve muscle redundancy and complete submaximal performance tasks such as wheelchair propulsion (Todorov, 2004; Erdemir et al., 2007). Therefore, the cost function that minimized the change in hand force and torques used to generate the simulations may not be the one used by the nervous system during wheelchair propulsion. However, similar dynamic cost functions (minimizing change in torque and/or hand force) have frequently been used to successfully reproduce upper extremity movements (e.g., Uno et al., 1989; Nakano et al., 1999; Ohta et al., 2004; Svinin et al., 2005). In addition, the cost function used ensured a smooth, stable motion in both the joint and handrim coordinate frames while limiting co-contraction similarly to functions that are based on reduction of muscle activations, forces or stresses. Thus, we believe that that the cost function used generated the essential characteristics of manual wheelchair propulsion to achieve our study goals. 


\section{CONCLUSIONS}

This study examined the influence of wheelchair seat position on upper extremity demand and found that metabolic cost, muscle stress and muscle antagonism were all near minimum values at positions with an anterior offset between $-0.14 \mathrm{~m}$ and $-0.03 \mathrm{~m}$ (hub-shoulder angle: between $-10^{\circ}$ and $-2.5^{\circ}$ ) and a superior offset between $-0.01 \mathrm{~m}$ and 0.03m (TDC elbow angle: between $110^{\circ}$ and $120^{\circ}$ ). Previous guidelines have recommended a seat positioned as posterior as possible. However, we found there is a limit to how far posterior to position the seat, as some measures of upper extremity demand increased once you move posterior beyond the $-10^{\circ}$ hub-shoulder angle. We also found that the influence of seat position on muscle antagonism is primarily dictated by the muscles crossing the glenohumeral joint. These results can provide guidelines for positioning the seat to help reduce upper extremity overuse injuries and pain, and thus improve the overall quality of life for wheelchair users. 


\section{Appendix}

Table A1: $\quad$ Upper extremity musculoskeletal model parameters. Fiber type composition values were based on Johnson et al. (1973). All other values were taken from Rankin et al. (2010) and Rankin et al. (2011).

\begin{tabular}{|c|c|c|c|c|c|c|c|c|}
\hline Muscle & Abbreviation & Origin & Insertion & $\begin{array}{c}\text { Peak } \\
\text { Isometric } \\
\text { Force } \\
\text { (N) }\end{array}$ & $\begin{array}{l}\text { Optimal } \\
\text { Fiber } \\
\text { Length } \\
\text { (m) }\end{array}$ & $\begin{array}{l}\text { Tendon } \\
\text { Slack } \\
\text { Length } \\
\text { (m) }\end{array}$ & $\begin{array}{l}\text { Pennation } \\
\text { Angle } \\
\text { (deg) }\end{array}$ & $\begin{array}{c}\text { Fiber Type } \\
\text { Composition } \\
\text { (\% Fast } \\
\text { Twitch) }\end{array}$ \\
\hline Anterior deltoid & DELT1 & Clavicle & Humerus & 1142.6 & 0.12 & 0.123 & 22 & 42.9 \\
\hline Middle deltoid & DELT2 & Scapula & Humerus & 1142.6 & 0.1078 & 0.1095 & 15 & 42.9 \\
\hline Posterior deltoid & DELT3 & Scapula & Humerus & 259.88 & 0.1367 & 0.038 & 18 & 42.9 \\
\hline Pectoralis major, clavicular head & PECM1 & Clavicle & Humerus & 364.41 & 0.1242 & 0.0228 & 17 & 57.7 \\
\hline Pectoralis major, sternocostal head portion 1 (sternum) & PECM2 & Thorax & Humerus & 515.41 & 0.1385 & 0.089 & 25 & 56.9 \\
\hline Pectoralis major, sternocostal head portion 2 (ribs) & PECM3 & Thorax & Humerus & 390.55 & 0.1385 & 0.152 & 25 & 56.9 \\
\hline Coracobrachialis & CORB & Scapula & Humerus & 242.46 & 0.0932 & 0.097 & 0 & 52.7 \\
\hline Teres major & TMAJ & Scapula & Humerus & 425.39 & 0.1624 & 0.02 & 16 & 49.5 \\
\hline Latissimus dorsi, thoracic portion & LAT1 & Thorax & Humerus & 389.1 & 0.254 & 0.12 & 25 & 49.5 \\
\hline Latissimus dorsi, lumbar portion & LAT2 & Thorax & Humerus & 389.1 & 0.2324 & 0.1765 & 19 & 49.5 \\
\hline Latissimus dorsi, iliac portion & LAT3 & Thorax & Humerus & 281.66 & 0.2789 & 0.1403 & 21 & 49.5 \\
\hline Subscapularis & SUBSC & Scapula & Humerus & 1377.81 & 0.0873 & 0.033 & 20 & 54.7 \\
\hline Infraspinatus & INFSP & Scapula & Humerus & 1210.84 & 0.0805 & 0.05 & 18.5 & 54.7 \\
\hline Teres minor & TMIN & Scapula & Humerus & 354.25 & 0.0741 & 0.0813 & 24 & 54.7 \\
\hline Supraspinatus & SUPSP & Scapula & Humerus & 487.82 & 0.0682 & 0.0595 & 7 & 40.7 \\
\hline Brachioradialis & BRD & Humerus & Radius & 261.33 & 0.1726 & 0.133 & 0 & 60.2 \\
\hline Brachialis & BRA & Humerus & Ulna & 987.26 & 0.0858 & 0.065 & 0 & 49.5 \\
\hline Biceps brachii, short head & BICshort & Scapula & Radius & 435.56 & 0.1321 & 0.2123 & 0 & 57.7 \\
\hline Biceps brachii, long head & BIClong & Scapula & Radius & 624.3 & 0.1557 & 0.3 & 0 & 57.7 \\
\hline Anconeus & ANC & Humerus & Ulna & 350 & 0.027 & 0.018 & 0 & 67.4 \\
\hline Triceps brachii, lateral head & TRIlat & Humerus & Ulna & 624.3 & 0.1138 & 0.098 & 9 & 67.4 \\
\hline Triceps brachii, medial head & TRImed & Humerus & Ulna & 624.3 & 0.1138 & 0.0908 & 9 & 67.4 \\
\hline Triceps brachii, long head & TRIlong & Scapula & Ulna & 798.52 & 0.134 & 0.217 & 12 & 67.4 \\
\hline Supinator & SUP & Ulna & Radius & 476 & 0.033 & 0.028 & 0 & 52.7 \\
\hline Pronator quadratus & PQ & Ulna & Radius & 75.48 & 0.0282 & 0.005 & 10 & 52.7 \\
\hline Pronator teres & $\mathrm{PT}$ & Humerus & Radius & 566.22 & 0.0492 & 0.098 & 10 & 52.7 \\
\hline
\end{tabular}




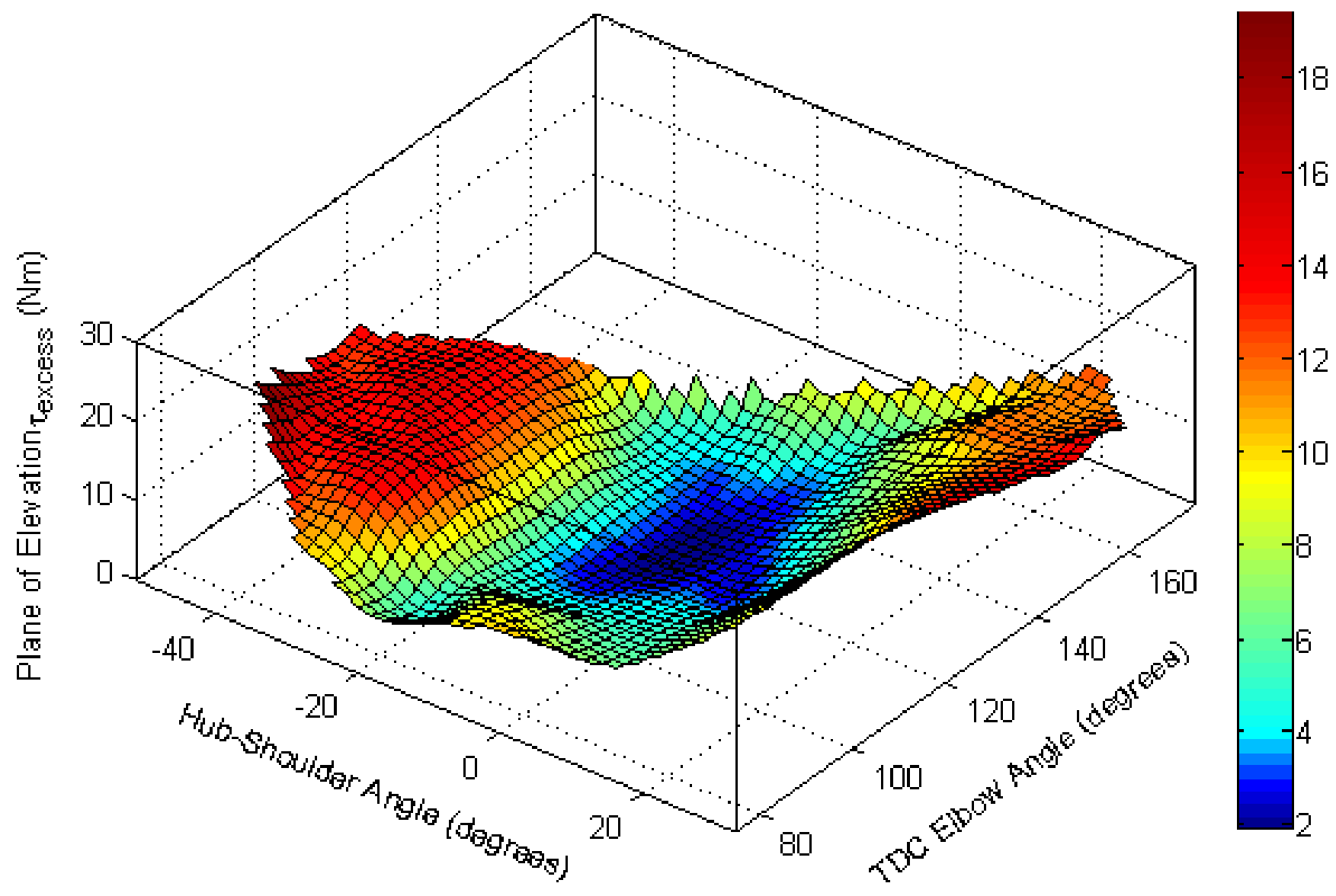

Figure A1: Plane of elevation excess torque versus seat position. Plane of elevation excess torque is the time-averaged difference between the total torque and the net torque, evaluated for the individual DOF defined by the shoulder plane of elevation. Seat position is defined by the hub-shoulder angle and the elbow angle when the hand is at TDC. 


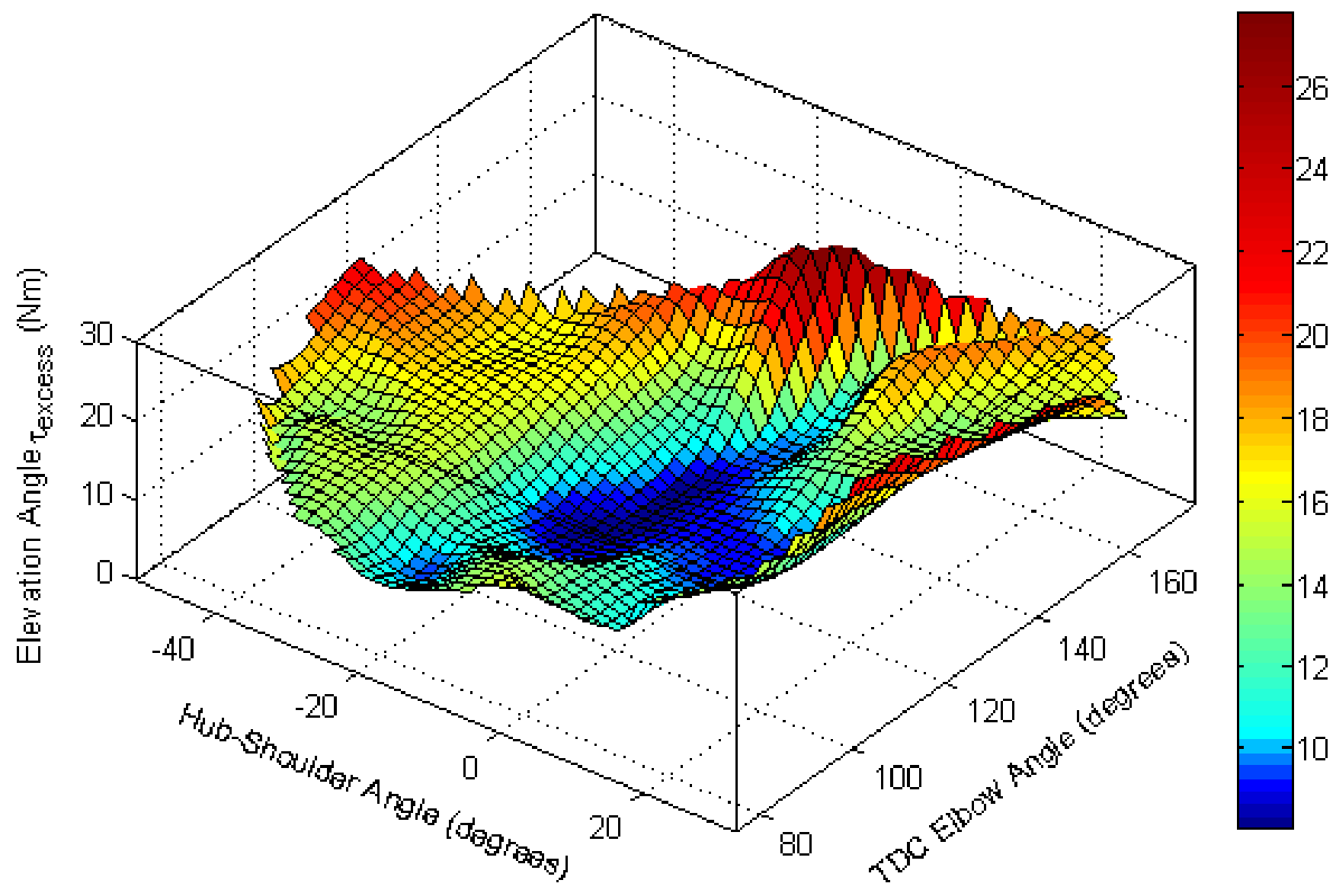

Figure A2: Elevation angle excess torque versus seat position. Elevation angle excess torque is the time-averaged difference between the total torque and the net torque, evaluated for the individual DOF defined by the shoulder elevation angle. Seat position is defined by the hub-shoulder angle and the elbow angle when the hand is at TDC. 


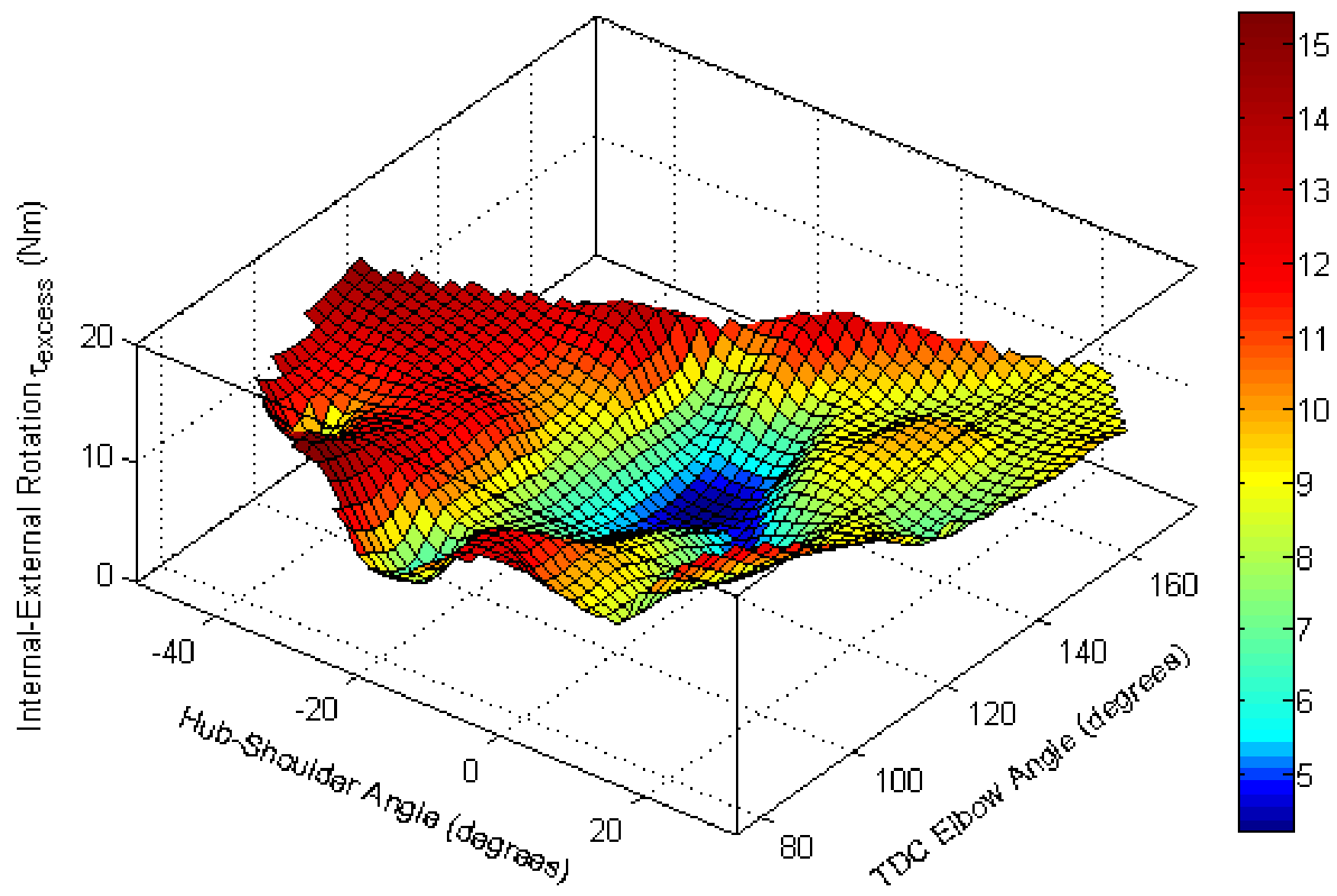

Figure A3: Internal-external rotation excess torque versus seat position. Internal-external rotation excess torque is the time-averaged difference between the total torque and the net torque, evaluated for the individual DOF defined by the shoulder internalexternal rotation. Seat position is defined by the hub-shoulder angle and the elbow angle when the hand is at TDC. 


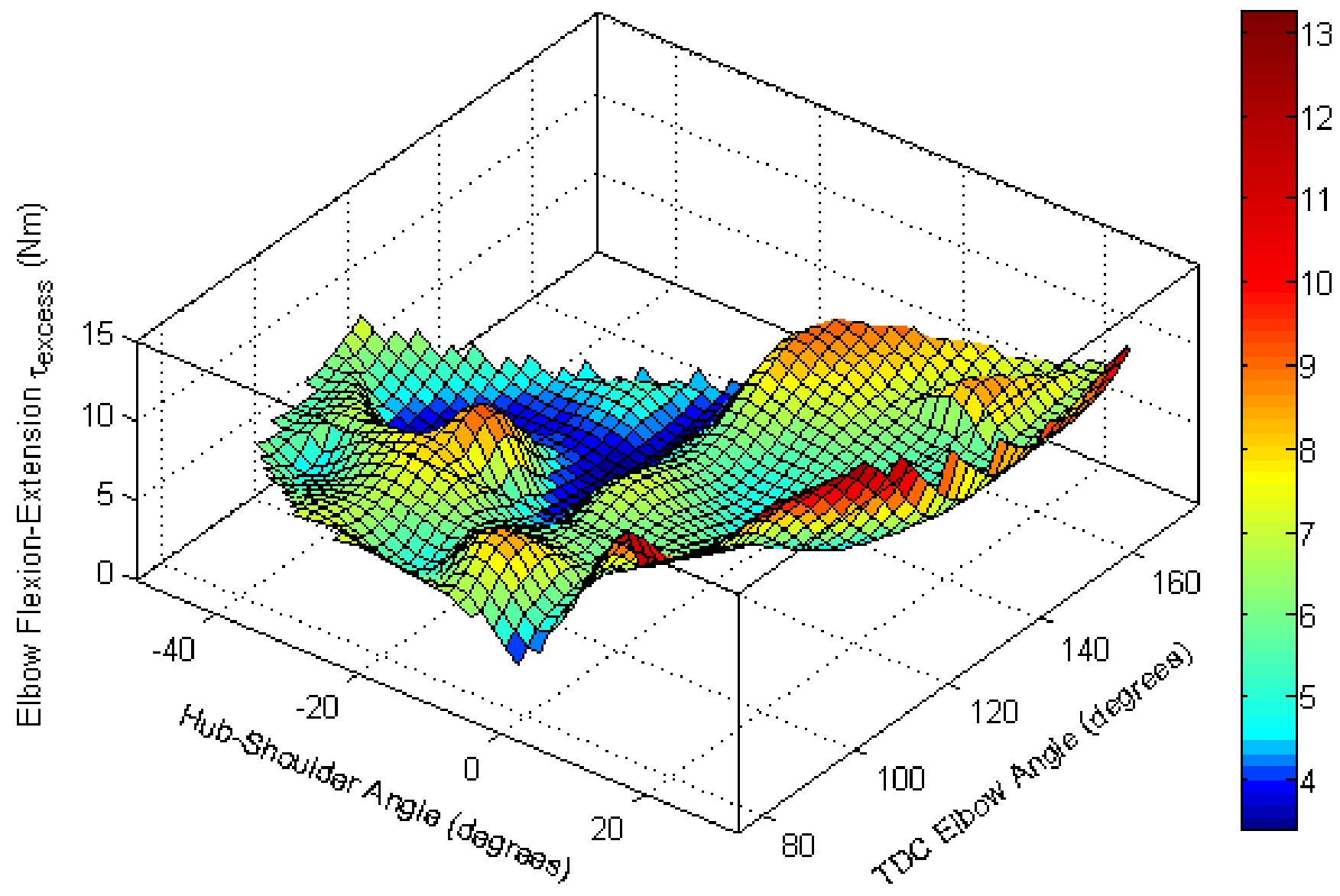

Figure A4: Elbow flexion-extension excess torque versus seat position. Elbow flexion-extension excess torque is the time-averaged difference between the total torque and the net torque, evaluated for the individual DOF defined by the flexion-extension at the elbow. Seat position is defined by the hub-shoulder angle and the elbow angle when the hand is at TDC. 


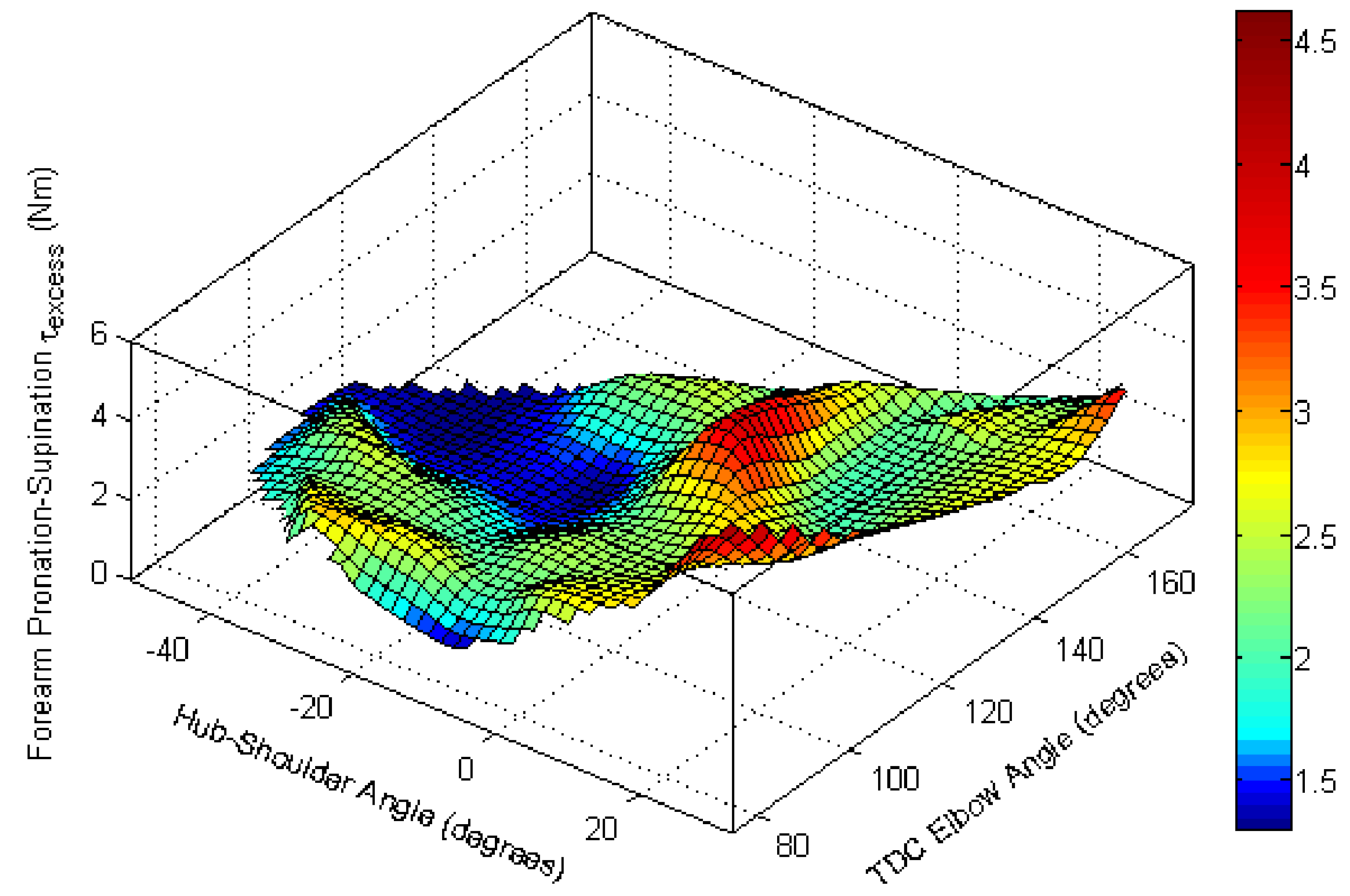

Figure A5: Forearm pronation-supination excess torque versus seat position. Forearm pronation-supination excess torque is the timeaveraged difference between the total torque and the net torque, evaluated for the individual DOF defined by the pronation-supination of the forearm. Seat position is defined by the hub-shoulder angle and the elbow angle when the hand is at TDC. 


\section{References}

Anderson, F. C. and Pandy, M. G. (2001). Dynamic optimization of human walking. $J$ Biomech Eng 123 (5), 381-90.

Boninger, M. L., Baldwin, M., Cooper, R. A., Koontz, A. and Chan, L. (2000). Manual wheelchair pushrim biomechanics and axle position. Arch Phys Med Rehabil 81 (5), 608-13.

Boninger, M. L., Koontz, A. M., Sisto, S. A., Dyson-Hudson, T. A., Chang, M., Price, R. and Cooper, R. A. (2005). Pushrim biomechanics and injury prevention in spinal cord injury: recommendations based on CULP-SCI investigations. J Rehabil Res Dev 42 (3 Suppl 1), 9-19.

Brubaker, C. E. (1986). Wheelchair prescription: an analysis of factors that affect mobility and performance. J Rehabil Res Dev 23 (4), 19-26.

Centers for Disease Control and Prevention (2009). Prevalence and most common causes of disability among adults -- United States, 2005. MMWR: Morbidity \& Mortality Weekly Report 58 (16), 421-426.

Chow, J. W., Millikan, T. A., Carlton, L. G., Chae, W. S., Lim, Y. T. and Morse, M. I. (2009). Kinematic and electromyographic analysis of wheelchair propulsion on ramps of different slopes for young men with paraplegia. Arch Phys Med Rehabil 90 (2), 271-8.

Cowan, R. E., Nash, M. S., Collinger, J. L., Koontz, A. M. and Boninger, M. L. (2009). Impact of surface type, wheelchair weight, and axle position on wheelchair propulsion by novice older adults. Arch Phys Med Rehabil 90 (7), 1076-83.

Erdemir, A., McLean, S., Herzog, W. and van den Bogert, A. J. (2007). Model-based estimation of muscle forces exerted during movements. Clin Biomech 22 (2), 13154.

Fey, N. P., Klute, G. K. and Neptune, R. R. (2012). Optimization of prosthetic foot stiffness to reduce metabolic cost and intact knee loading during below-knee amputee walking: a theoretical study. J Biomech Eng (in press).

Finley, M. A., Rasch, E. K., Keyser, R. E. and Rodgers, M. M. (2004). The biomechanics of wheelchair propulsion in individuals with and without upper-limb impairment. J Rehabil Res Dev 41 (3B), 385-394.

Fregly, B. J., Boninger, M. L. and Reinkensmeyer, D. J. (2012). Personalized neuromusculoskeletal modeling to improve treatment of mobility impairments: a perspective from European research sites. J Neuroeng Rehabil 918.

Goffe, W. L., Ferrier, G. D. and Rogers, J. (1994). Global Optimization of Statistical Functions With Simulated Annealing. J Econometrics 60 65-99. 
Goosey-Tolfrey, V. L. and Kirk, J. H. (2003). Effect of push frequency and strategy variations on economy and perceived exertion during wheelchair propulsion. Eur J Appl Physiol 90 (1-2), 154-158.

Goosey, V. L., Campbell, I. G. and Fowler, N. E. (1998). The relationship between threedimensional wheelchair propulsion techniques and pushing economy. J Appl Biomech 14 (4), 412-427.

Gorce, P. and Louis, N. (2012). Wheelchair propulsion kinematics in beginners and expert users: influence of wheelchair settings. Clin Biomech 27 (1), 7-15.

Guo, L. Y., Su, F. C. and An, K. N. (2006). Effect of handrim diameter on manual wheelchair propulsion: mechanical energy and power flow analysis. Clin Biomech 21 (2), 107-15.

Guo, L. Y., Su, F. C., Wu, H. W. and An, K. N. (2003). Mechanical energy and power flow of the upper extremity in manual wheelchair propulsion. Clin Biomech 18 (2), 106-14.

Gutierrez, D. D., Mulroy, S. J., Newsam, C. J., Gronley, J. K. and Perry, J. (2005). Effect of fore-aft seat position on shoulder demands during wheelchair propulsion: part 2. An electromyographic analysis. J Spinal Cord Med 28 (3), 222-9.

Gutierrez, D. D., Thompson, L., Kemp, B. and Mulroy, S. J. (2007). The relationship of shoulder pain intensity to quality of life, physical activity, and community participation in persons with paraplegia. J Spinal Cord Med 30 (3), 251-5.

Haisma, J. A., van der Woude, L. H., Stam, H. J., Bergen, M. P., Sluis, T. A. and Bussmann, J. B. (2006). Physical capacity in wheelchair-dependent persons with a spinal cord injury: a critical review of the literature. Spinal Cord 44 (11), 642-52.

Happee, R. and van der Helm, F. C. (1995). The control of shoulder muscles during goal directed movements, an inverse dynamic analysis. J Biomech 28 (10), 1179-91.

Hintzy, F. and Tordi, N. (2004). Mechanical efficiency during hand-rim wheelchair propulsion: effects of base-line subtraction and power output. Clin Biomech 19 (4), 343-9.

Holzbaur, K. R., Murray, W. M. and Delp, S. L. (2005). A model of the upper extremity for simulating musculoskeletal surgery and analyzing neuromuscular control. Ann Biomed Eng 33 (6), 829-840.

Hughes, C. J., Weimar, W. H., Sheth, P. N. and Brubaker, C. E. (1992). Biomechanics of wheelchair propulsion as a function of seat position and user-to-chair interface. Arch Phys Med Rehabil 73 (3), 263-9.

Hurd, W. J., Morrow, M. M., Kaufman, K. R. and An, K. N. (2008). Biomechanic evaluation of upper-extremity symmetry during manual wheelchair propulsion over varied terrain. Arch Phys Med Rehabil 89 (10), 1996-2002. 
Janssen, T. W., Dallmeijer, A. J., Veeger, D. J. and van der Woude, L. H. (2002). Normative values and determinants of physical capacity in individuals with spinal cord injury. J Rehabil Res Dev 39 (1), 29-39.

Johnson, M. A., Polgar, J., Weightman, D. and Appleton, D. (1973). Data on the distribution of fibre types in thirty-six human muscles. An autopsy study. $J$ Neurol Sci 18 (1), 111-29.

Kaye, H. S., Kang, T. and LaPlante, M. (2000). Mobility Device Use in the United States. Disability Statistics Report, (14). Washington, DC: U. S. Department of Education, National Institute on Disability and Rehabilitation Research.

Kotajarvi, B. R., Sabick, M. B., An, K. N., Zhao, K. D., Kaufman, K. R. and Basford, J. R. (2004). The effect of seat position on wheelchair propulsion biomechanics. $J$ Rehabil Res Dev 41 (3B), 403-413.

Kwarciak, A. M., Sisto, S. A., Yarossi, M., Price, R., Komaroff, E. and Boninger, M. L. (2009). Redefining the Manual Wheelchair Stroke Cycle: Identification and Impact of Nonpropulsive Pushrim Contact. Arch Phys Med Rehabil 90 (1), 20-26.

Kwarciak, A. M., Turner, J. T., Guo, L. and Richter, W. M. (2012). The effects of four different stroke patterns on manual wheelchair propulsion and upper limb muscle strain. Disabil Rehabil Assist Technol (in press).

Lin, C. J., Lin, P. C., Su, F. C. and An, K. N. (2009). Biomechanics of wheelchair propulsion. J Mech Med Biol 9 (2), 229-242.

Lin, H. T., Su, F. C., Wu, H. W. and An, K. N. (2004). Muscle forces analysis in the shoulder mechanism during wheelchair propulsion. P I Mech Eng H-J Eng Med 218 (H4), 213-221.

Liu, M. Q., Anderson, F. C., Pandy, M. G. and Delp, S. L. (2006). Muscles that support the body also modulate forward progression during walking. J Biomech 39 (14), 2623-30.

Louis, N. and Gorce, P. (2010). Surface electromyography activity of upper limb muscle during wheelchair propulsion: Influence of wheelchair configuration. Clin Biomech 25 (9), 879-85.

Masse, L. C., Lamontagne, M. and O'Riain, M. D. (1992). Biomechanical analysis of wheelchair propulsion for various seating positions. J Rehabil Res Dev 29 (3), 1228.

McGowan, C. P., Kram, R. and Neptune, R. R. (2009). Modulation of leg muscle function in response to altered demand for body support and forward propulsion during walking. J Biomech 42 (7), 850-6.

Mercer, J. L., Boninger, M., Koontz, A., Ren, D., Dyson-Hudson, T. and Cooper, R. (2006). Shoulder joint kinetics and pathology in manual wheelchair users. Clin Biomech 21 (8), 781-9. 
Miller, R. H., Umberger, B. R., Hamill, J. and Caldwell, G. E. (2012). Evaluation of the minimum energy hypothesis and other potential optimality criteria for human running. P Roy Soc B-Biol Sci 279 (1733), 1498-505.

Mulroy, S. J., Farrokhi, S., Newsam, C. J. and Perry, J. (2004). Effects of spinal cord injury level on the activity of shoulder muscles during wheelchair propulsion: an electromyographic study. Arch Phys Med Rehabil 85 (6), 925-34.

Mulroy, S. J., Newsam, C. J., Gutierrez, D. D., Requejo, P., Gronley, J. K., Haubert, L. L. and Perry, J. (2005). Effect of fore-aft seat position on shoulder demands during wheelchair propulsion: part 1. A kinetic analysis. J Spinal Cord Med 28 (3), 21421.

Nakano, E., Imamizu, H., Osu, R., Uno, Y., Gomi, H., Yoshioka, T. and Kawato, M. (1999). Quantitative examinations of internal representations for arm trajectory planning: minimum commanded torque change model. J Neurophysiol 81 (5), 2140-55.

Newsam, C. J., Mulroy, S. J., Gronley, J. K., Bontrager, E. L. and Perry, J. (1996). Temporal-spatial characteristics of wheelchair propulsion. Effects of level of spinal cord injury, terrain, and propulsion rate. Am J Phys Med Rehabil 75 (4), 292-9.

Ohta, K., Svinin, M. M., Luo, Z., Hosoe, S. and Laboissiere, R. (2004). Optimal trajectory formation of constrained human arm reaching movements. Biol Cybern 91 (1), 23-36.

Paralyzed Veterans of America Consortium for Spinal Cord Medicine (2005). Preservation of upper limb function following spinal cord injury: a clinical practice guideline for health-care professionals. J Spinal Cord Med 28 (5), 43470.

Pentland, W. E. and Twomey, L. T. (1994). Upper limb function in persons with long term paraplegia and implications for independence: Part I. Paraplegia 32 (4), 211-8.

Raasch, C. C., Zajac, F. E., Ma, B. and Levine, W. S. (1997). Muscle coordination of maximum-speed pedaling. $J$ Biomech 30 (6), 595-602.

Rankin, J. W., Kwarciak, A. M., Mark Richter, W. and Neptune, R. R. (2010). The influence of altering push force effectiveness on upper extremity demand during wheelchair propulsion. J Biomech 43 (14), 2771-9.

Rankin, J. W., Kwarciak, A. M., Richter, W. M. and Neptune, R. R. (2012). The influence of propulsion technique on upper extremity muscle demand: a simulation study. Clin Biomech (in press). 
Rankin, J. W. and Neptune, R. R. (2008). A theoretical analysis of an optimal chainring shape to maximize crank power during isokinetic pedaling. J Biomech 41 (7), 1494-1502.

Rankin, J. W. and Neptune, R. R. (2010). The influence of seat configuration on maximal average crank power during pedaling: a simulation study. J Appl Biomech 26 (4), 493-500.

Rankin, J. W., Richter, W. M. and Neptune, R. R. (2011). Individual muscle contributions to push and recovery subtasks during wheelchair propulsion. $J$ Biomech 44 (7), 1246-52.

Requejo, P., Mulroy, S., Haubert, L. L., Newsam, C., Gronley, J. and Perry, J. (2008a). Evidence-Based Strategies to Preserve Shoulder Function in Manual Wheelchair Users with Spinal Cord Injury. Top Spinal Cord Inj Rehabil 13 (4), 86-119.

Requejo, P. S., Lee, S. E., Mulroy, S. J., Haubert, L. L., Bontrager, E. L., Gronley, J. K. and Perry, J. (2008b). Shoulder muscular demand during lever-activated vs pushrim wheelchair propulsion in persons with spinal cord injury. J Spinal Cord Med 31 (5), 568-77.

Rice, I., Gagnon, D., Gallagher, J. and Boninger, M. (2010). Hand rim wheelchair propulsion training using biomechanical real-time visual feedback based on motor learning theory principles. J Spinal Cord Med 33 (1), 33-42.

Richter, W. M. (2001). The effect of seat position on manual wheelchair propulsion biomechanics: a quasi-static model-based approach. Med Eng Phys 23 (10), 70712.

Richter, W. M., Kwarciak, A. M., Guo, L. and Turner, J. T. (2011). Effects of singlevariable biofeedback on wheelchair handrim biomechanics. Arch Phys Med Rehabil 92 (4), 572-7.

Richter, W. M., Rodriguez, R., Woods, K. R. and Axelson, P. W. (2007). Stroke pattern and handrim biomechanics for level and uphill wheelchair propulsion at selfselected speeds. Arch Phys Med Rehabil 88 (1), 81-7.

Riggins, M. S., Kankipati, P., Oyster, M. L., Cooper, R. A. and Boninger, M. L. (2011). The relationship between quality of life and change in mobility 1 year postinjury in individuals with spinal cord injury. Arch Phys Med Rehabil 92 (7), 1027-33.

Robertson, R. N., Boninger, M. L., Cooper, R. A. and Shimada, S. D. (1996). Pushrim forces and joint kinetics during wheelchair propulsion. Arch Phys Med Rehabil 77 (9), 856-64.

Rodgers, M. M., Keyser, R. E., Rasch, E. K., Gorman, P. H. and Russell, P. J. (2001). Influence of training on biomechanics of wheelchair propulsion. $J$ Rehabil Res Dev 38 (5), 505-11. 
Sabick, M. B., Kotajarvi, B. R. and An, K. N. (2004). A new method to quantify demand on the upper extremity during manual wheelchair propulsion. Arch Phys Med Rehabil 85 (7), 1151-9.

Sasaki, K. and Neptune, R. R. (2006). Muscle mechanical work and elastic energy utilization during walking and running near the preferred gait transition speed. Gait Posture 23 (3), 383-90.

Svinin, M., Masui, Y., Luo, Z. W. and Hosoe, S. (2005). On the dynamic version of the minimum hand jerk criterion. J Robotic Syst 22 (11), 661-676.

Todorov, E. (2004). Optimality principles in sensorimotor control. Nat Neurosci 7 (9), $907-15$.

Umberger, B. R. (2010). Stance and swing phase costs in human walking. $J$ R Soc Interface 7 (50), 1329-40.

Umberger, B. R., Gerritsen, K. G. and Martin, P. E. (2003). A model of human muscle energy expenditure. Comput Methods Biomech Biomed Engin 6 (2), 99-111.

Umberger, B. R., Gerritsen, K. G. and Martin, P. E. (2006). Muscle fiber type effects on energetically optimal cadences in cycling. $J$ Biomech 39 (8), 1472-1479.

Uno, Y., Kawato, M. and Suzuki, R. (1989). Formation and control of optimal trajectory in human multijoint arm movement: Minimum torque-change model. Biol Cybern 61 (2), 89-101.

van der Helm, F. C. and Veeger, H. E. (1996). Quasi-static analysis of muscle forces in the shoulder mechanism during wheelchair propulsion. J Biomech 29 (1), 39-52.

van der Woude, L. H., Veeger, D. J., Rozendal, R. H. and Sargeant, T. J. (1989). Seat height in handrim wheelchair propulsion. J Rehabil Res Dev 26 (4), 31-50.

van der Woude, L. H. V., Bouw, A., van Wegen, J., van As, H., Veeger, D. and de Groot, S. (2009). Seat height: Effects on submaximal hand rim wheelchair performance during spinal cord injury rehabilitation. J Rehabil Med 41 (3), 143-149.

Veeger, H. E. (1999). Biomechanics of Manual Wheelchair Propulsion. In: Biomedical Aspects of Manual Wheelchair Propulsion: The State of the Art II.L. H. Van der Woude, M. T. Hopman and C. H. Kemenade. Amsterdam, The Netherlands, IOS Press. 5: 86-95.

Veeger, H. E., Rozendaal, L. A. and van der Helm, F. C. (2002). Load on the shoulder in low intensity wheelchair propulsion. Clin Biomech 17 (3), 211-8.

Wei, S. H., Huang, S., Jiang, C. J. and Chiu, J. C. (2003). Wrist kinematic characterization of wheelchair propulsion in various seating positions: implication to wrist pain. Clin Biomech 18 (6), S46-52. 
Winters, J. M. and Stark, L. (1988). Estimated mechanical properties of synergistic muscles involved in movements of a variety of human joints. J Biomech 21 (12), 1027-41.

Wu, G., van der Helm, F. C., Veeger, H. E., Makhsous, M., Van Roy, P., Anglin, C., Nagels, J., Karduna, A. R., McQuade, K., Wang, X., Werner, F. W. and Buchholz, B. (2005). ISB recommendation on definitions of joint coordinate systems of various joints for the reporting of human joint motion--Part II: shoulder, elbow, wrist and hand. J Biomech 38 (5), 981-992.

Zajac, F. E. (1989). Muscle and tendon: properties, models, scaling, and application to biomechanics and motor control. Crit Rev Biomed Eng 17 (4), 359-411.

Zajac, F. E., Neptune, R. R. and Kautz, S. A. (2002). Biomechanics and muscle coordination of human walking. Part I: introduction to concepts, power transfer, dynamics and simulations. Gait Posture 16 (3), 215-32.

Zajac, F. E., Neptune, R. R. and Kautz, S. A. (2003). Biomechanics and muscle coordination of human walking: part II: lessons from dynamical simulations and clinical implications. Gait Posture 17 (1), 1-17. 


\section{Vita}

Jonathan Steven Slowik was born and raised in the suburbs of Chicago, Illinois. After graduating from Wheeling High School in June 2002, he entered the Massachusetts

Institute of Technology. In June 2006, he received the Bachelor of Science in Mechanical Engineering, and subsequently joined Orbital Sciences Corporation in Dulles, Virginia. He remained there until entering the Graduate School at The University of Texas at Austin in August 2010.

Email address: jsslowik@alum.mit.edu

This thesis was typed by the author. 